\author{
R.D. Vengrenovich, B.V. Ivanskii, M.O. Stasyk, S.V. Yarema, A.V. Moskaliuk, \\ I.I. Panko, V.I. Kryvetskyi, I.V. Fesiv
}

\title{
Ostwald Ripening of Nanodispersed Phases in Metal Alloys (review)
}

\author{
Yuriy Fedkovych Chernivtsi National University, Chernivtsi, Ukraine, e-mail: office@chnu.edu.ua
}

\begin{abstract}
The review deals with analysis of the kinetics of Ostwald ripening of nanodispersed phases in metal alloys when the growth (dissolution) of the nanoparticles of the reinforcing phase is controlled simultaneously by the matrix diffusion, diffusion through the dislocation tubes and the rate of the atoms transition through the interphase boundary (Wagner's mechanism of growth). As a rule, different mechanisms of the nanoparticles growth (dissolution) are simultaneously employed in the process of the particles ripening while the number of the mechanisms involved in the growth (one, two or three) depends on various factors such as: chemical composition of the nanodispersed phases, conditions of exploitation (changes in mechanical loads, temperature regimes, environmental conditions), technological conditions of synthesis, etc. It has been shown that when the growth (dissolution) of nanoparticles in the Ostwald ripening process is controlled simultaneously with the matrix diffusion $D_{v}$ and the diffusion coefficient through the dislocations $D_{d}$, the corresponding function of particles size distribution will depend on one parameter $x$ varying within the limits $0 \leq x \leq 1$, where $x$ - determines the relation between the diffusive $j_{v}$ and dislocation $j_{d}$ fluxes. In the case when three mechanisms of growth (dissolution) are involved, the general flux $j$ corresponding to the mass transfer between the particles and the matrix will consist of three parts $j=j_{v}+j_{d}+j_{i}$, where the kinetic component $j_{i}$ is determined by the kinetic coefficient $\beta$. Then the corresponding function of the nanoparticles size distribution will depend on the two parameters $x$ and $y$ which determine the relationship between the diffusive $\left(j^{\prime}=j_{v}+j_{d}\right)$ and the kinetic flux $(0 \leq x, y \leq 1)$. The possibility of practical implementation of the proposed mechanisms of growth of nanoparticles in the Ostwald ripening process can be confirmed or declined by a comparison between the experimental and theoretical data. As seen from the comparison between some experimental histograms with the lines built theoretically, the proposed mechanisms of growth of the dispersed phase nanoparticles seem realistic.

Keywords: nanoparticle, Ostwald ripening, Lifshitz-Slezov-Wagner theory, nanocrystal, cluster, size distribution function.
\end{abstract}

Work arrived to the editor 02.06.2019.; accepted for printing 15.06.2019.

\section{Introduction}

A development of new construction materials based on the metal alloys reinforced with some nanodispersed phases is becoming more feasible because of recent advances in the nanotechnologies (NT). NT is a new interdisciplinary and very promising field, which can lead to many important applications ranged from new effective drugs and highly-productive computers to the 'molecular productions' working on the vertical principles when a required target nanostructure is being constructed from the separate atoms and molecules. It is especially important that NT can develop, employ and improve the technological strategies resembling those, which exist in nature. Thus, the diversity of nature generates the technological diversity in the methods of nanostructures (NS) synthesis [1]. Following physical methods can be utilized to obtain the composite materials based on the nanodispersed phases consisting of nanoparticles (NP) or nanocrystals (NC) or to synthesize new nanomaterials to be used as the elementary base for the nanodevices of future: mechanical grinding followed by compacting of the powders by high pressure and heating; fast hardening of the melts; some lithographic methods, and, especially, the molecular-beam epitaxy method that can be used to obtain the quantum dots by the Stranski-Krastanov methods.

No matter which chemical or physical method was used to obtain NS, the size variation should be kept as narrow as possible so that the value of dispersion would be minimal. However, Ostwald ripening (OR) occurring in such systems can result in some widening of the particles size range and increasing the dispersion. Thus, size variety of the NS particles becomes wider and 
imbalanced because of OR, which may lead to partial or complete deterioration of important physico-chemical properties of NS. This is an unwanted result of OR in NS.

According to classical approach, there are three stages in formation of a new phase: origination of new phase centres (germs), their independent growth followed by interlacing and mutual interference between various germs. The latter stage is also known as the late period of a new phase development or OR [2]. During this phase, the greater surface curvature particles are dissolving and gradually disappear because of diffusive transportation of matter towards the particles with a lesser surface curvature (Gibbs-Thomson effect). This process causes continuous increase in the average size of NC. First general theory of OR was proposed for this diffusive mass transfer by Lifschitz and Slezov [3, 4]. According to their theory, the increase in the NC average size is limited by the coefficient of bulk or matrix diffusion $D_{v}$. Then the temporal change in the average size of NC $\langle r\rangle$ can be represented as $t^{1 / 3}$ while the general particles size distribution can be described as the Lifschitz-Slezov function (LS).

Another approach to description of NC growth was proposed by Wagner [5]. This mechanism is limited by the rate of chemical reaction controlling formation of new chemical bonds on the particles surface. According to this approach, NC growing is controlled by the kinetics coefficient $\beta ;\langle r\rangle$ depends on time as $t^{1 / 2}$ while the size distribution corresponds to the Wagner function (W). A combination of the two theories was developed in [3-5] and this approach is known as the Lifschitz-Slezov-Wagner theory (LSW). This theory was also employed to resolve other conjugated problems related to OR controlled by the diffusion on the grain edges [6, 7], surface diffusion [8, 9], diffusion inside dislocation tubes [10-14] and some others [15-24]. As seen from comparison between the LSW data and experimental results, in some cases this approach can be satisfactory applied to description of temporal changes in average size of $\mathrm{NC}$ while further improvement of the theory is needed in some other cases.

Taking into account the above issues, two approaches (diffusive and Wagner's mechanisms) were used simultaneously in [25-27] to analyze growing of NC. This modified LSW mechanism resulted in a better particles size distribution (GDLSW) [25], which can embrace a wider array of experimental data comparing to those analyzed in LS and W mechanisms separately.

However, a deceleration of dislocations on $\mathrm{NC}$ followed by their fixation will occur in case some free dislocations are present in the matrix, which generates some coherent-bonded deposition of the reinforcing phase. As a result, the mobile dislocations can interact with the elastic stress fields distributed near $\mathrm{NC}$ and cause the deceleration and fixation. Besides, a difference in specific volumes of the dispersed deposition and the matrix also contributes into this process. Then the diffusion along dislocations starts to act as the governing factor instead of the matrix diffusion. The dislocation diffusion can be represented as a process occurring inside the dislocation tubes with section $q\left(b^{2} \leq q \leq 60 b^{2}\right)$, where $b$ is Burgers vector.

Then the coherence between NC and the matrix is further worsening in course of their growing and causes separation of initially fixed dislocations. Afterwards, they will move until new capturing and fixation by the elastic stress field would occur near another NC that is still coherent with the matrix.

This review deals with results of some theoretical investigations of OR kinetics related to nanoparticles in the metal alloys when the reinforcing phase particles growing process is controlled by dislocation-Wagner's mechanism with next involvement of the matrix diffusion.

All calculations were made by the modified LSW theory $[25,27,28]$ and using the method described in [29].

\section{Ostwald ripening under the dislocation-Wagner's mechanism of growing. Wagner-Vengrenovich distribution}

When some free dislocations are present in the matrix, some fine-dispersed depositions will be coherent bounded with them. Then, the mobile dislocations will interact with the elastic stress fields appearing near the fine dispersed depositions of the reinforcing phase particles because their specific volume differs from that of the matrix matter. As a result, deceleration and fixation of the depositions on the particles will occur. According to this mechanism of the particles growth, a flux of the atoms along the dislocations can be represented as [10]:

$$
j_{d}=D_{d} 2 Z q \frac{\langle C\rangle-C_{r}}{r},
$$

where $D_{d}$ - the coefficient of diffusion along the dislocations, $Z$ - the number of dislocations across NC ( $Z=$ const $), q$ - the pipe section area, $\langle C\rangle-$ the average bulk concentration of the diffusing atoms, $C_{r}=C_{\infty} \exp \left(2 \sigma v_{m} / r k T\right) \approx C_{\infty}\left(1+2 \sigma v_{m} / r k T\right) \quad-\quad$ the concentration of the solute's atoms on the interphase with a cluster with radius $r$ (Thomson formula), $C_{\infty}-$ the equilibrium concentration at given temperature $T, v_{m}-$ the volume of the solute atom.

If growing of a $\mathrm{NC}$ is controlled by the dislocationWagner's mechanism of mass transfer, the total flux of the atoms towards (outwards) NC will consist of two parts [30]:

$$
j=j_{d}+j_{i}
$$

where $j_{d}$ can be found from (1) while $j_{i}$ represents the Wagner's part of the flux equal to the number of atoms participating in the process of formation of chemical bonds on the cluster surface over the unit of time [5]

$$
j_{i}=4 \pi r^{2} \beta\left(\langle C\rangle-C_{r}\right) \text {, }
$$


where $\beta$ - the kinetics coefficient.

Let us use the continuity equation to determine the size distribution function $f(r, t)$

$$
\frac{\partial f(r, t)}{\partial t}+\frac{\partial}{\partial r}[f(r, t) \cdot \boldsymbol{\Phi}=0
$$

where $\delta E d r / d t$ - the rate of growth for a cluster with radius $r$. The rate of growth can be found from

$$
\frac{d}{d t}\left(\frac{4}{3} \pi r^{3}\right)=j v_{m}
$$

where $j$ is taken from (2).

Having $j_{d}$ and $j_{i}$, the rate of growth can be found from (5) as

$\frac{d r}{d t}=\frac{1}{4 \pi r^{2}}\left[D_{d} 2 Z q \frac{\left(\langle C\rangle-C_{r}\right)}{r}+4 \pi r^{2} \beta\left(\langle C\rangle-C_{r}\right)\right]$,

where $\langle C\rangle-C_{r}=\frac{2 \sigma v_{m}}{k T}\left(\frac{1}{r_{k}}-\frac{1}{r}\right), r_{k}-$ the critical radius, according to the LSW theory it is equal to the average radius $(\langle r\rangle)$.

The growth rate function (6) should be expressed through the fluxes $j_{d}$ and $j_{i}$ [30] in order to find an analytical form of the function determining cluster size distribution with account to the characteristic features of the Wagner's (W) [5] and the Vengrenovich's (V) [12] distributions

$$
\frac{j_{d}}{j_{i}}=\frac{x}{1-x}
$$

where $x$ - a part of the flux $j_{d}$ in the total flux $j$ : $x=j_{d} / j ;(1-x)-$ a part of the flux $j_{i}$ in the total flux $j: 1-x=j_{i} / j$. Taking into account that expressions (1) and (3) are valid for the NC with any radius $r$, including those with the maximal size $r_{g}[25,26,29]$, the rate of growth (6) can be written as

$$
\frac{d r}{d t}=\frac{A^{*}}{r}\left(\frac{x}{1-x} \frac{1}{u^{3}}+1\right)\left(\frac{r}{r_{k}}-1\right),
$$

where $A^{*}=2 \sigma v_{m}^{2} C_{\infty} \beta / k T, u=r / r_{g}$, or

$$
\frac{d r}{d t}=\frac{B^{*}}{r^{4}}\left(1+\frac{1-x}{x} u^{3}\right)\left(\frac{r}{r_{k}}-1\right)
$$

where $B^{*}=2 \sigma v_{m}^{2} C_{\infty} Z q D_{d} / \pi k T$.

The formula (8) describes the NC growth rate depending on the kinetic flux $j_{i}$ (the rate of establishing new chemical bonds) with $(1-x)$ as a contribution made by the diffusive part of the total flux $(x<1)$ while the rate of growth according to (9) is controlled by the diffusive flux $j_{d}$ with $x$ as a contribution made by the kinetic flux $(x>0)$.

The ratio $r_{g} / r_{k}$ corresponding to the value of the locking point $u_{0}\left(u_{0}=r_{g} / r_{k}\right)$ [3] can be found by using the growth rate formulas (8) and (9). Having defined a value of $u_{0}$, the equations (8) and (9) can be integrated and the temporal dependencies of $r_{g}$ and $r_{k}$ can be determined. Thus, the analytical form of the size distribution function can be obtained by separation of variables in the continuity equation (4). According to [29], the ratio $r_{g} / r_{k}\left(u_{0}\right)$ can be found from

$$
\frac{d}{d r}\left(\frac{\kappa}{r}\right)_{r=r_{g}}=0
$$

Then it can be obtained from (10) that

$$
\frac{r_{g}}{r_{k}}=\frac{2+3 x}{1+3 x} \text {. }
$$

Taking (8) $r=r_{g}(u=1)$ (see (8)) and substituting $r_{g} / r_{k}$ with its value from (11), after integrating one can get

$r_{g}^{2}=\frac{2 A^{*}}{(1-x)(1+3 x)} t, r_{k}^{2}=\frac{2 A^{*}(1+3 x)}{(1-x)(2+3 x)^{2}} t$.

The equations (12) represent temporal dependencies of the maximal $r_{g}$ and critical $r_{k}$ radiuses of NC under conditions controlled by the kinetic coefficient $\beta$ with $x$ as a contribution made by the dislocation diffusion.

If $x=0, \mathrm{NC}$ growing is completely controlled by the rate of new chemical bonds establishing [5]

$$
r_{g}^{2}=2 A^{*} t, \quad r_{k}^{2}=\frac{1}{2} A^{*} t, \quad \frac{r_{g}}{r_{k}}=2 .
$$

Similarly, it can be obtained from (9) that

$$
r_{g}^{5}=\frac{5 B^{*}}{x(1+3 x)} t, \quad r_{k}^{5}=\frac{5 B^{*}(1+3 x)^{4}}{x(2+3 x)^{5}} t .
$$

Equation (14) represents the temporal dependencies of $r_{g}$ and $r_{k}$ under such conditions when the dislocation diffusion coefficient $D_{d}$ acts as the limiting factor and $(1-x)$ is a contribution of that part of the total flux, which is controlled by the rate of establishing of new chemical bonds on the surface of NC.

If $x=1, \mathrm{NC}$ growth is controlled completely by diffusion of the solute atoms along the dislocation tubes $[10,12]$

$$
r_{g}^{5}=\frac{5}{4} B^{*} t, \quad r_{k}^{5}=\left(\frac{4}{5}\right)^{4} B^{*} t, \quad \frac{r_{g}}{r_{k}}=\frac{5}{4} .
$$

Then the NC size distribution function should be written as a product of two other functions [29]

$$
f(r, t)=\varphi\left(r_{g}\right) g^{\prime}(u),
$$

where $r_{g}=\psi(t)$.

Basing on the mass conservation law for the $\mathrm{NC}$ dispersed phase, we can get

$$
M=\frac{4}{3} \pi \rho \int_{0}^{r_{g}} r^{3} f(r, t) d r,
$$

and after substitution of (16) into the above equation

$$
\varphi\left(r_{g}\right)=\frac{Q}{r_{g}^{4}},
$$

where $Q=3 M /\left(4 \pi \rho \int_{0}^{1} u^{3} g^{\prime}(u) d u\right)$.

Taking (18) into consideration, the size distribution function (16) will be written as 
R.D. Vengrenovich, B.V. Ivanskii, M.O. Stasyk, S.V. Yarema, A.V. Moskaliuk, I.I. Panko, V.I. Kryvetskyi, I.V. Fesiv

$$
f(r, t)=\frac{1}{r_{g}^{4}} g(u)
$$

where

$$
g(u)=Q g^{\prime}(u),
$$

$g(u)$ - the sought function of relative sizes distribution describing the NC growth process controlled by both dislocation and Wagner's mass transfer mechanisms. Hereafter it is referred to as the Wagner-Vengrenovich function since the separate distributions corresponding to each of these two mechanisms were published before by Wagner [5] and Vengrenovich [12].

The continuity equation (4) with substitution of $f(r, t)$ and $\delta$ with their values from (16) and (18) (or
(19)) correspondingly should be used to define function $g^{\prime}(u)$. Let us separate the variables in (4) at transition from differentiation by $r$ and $t$ to differentiation by $u$

$$
\frac{d g^{\prime}(u)}{g^{\prime}(u)}=-\frac{4 v_{g} u^{2}+v-u \frac{d v}{d u}}{u^{3} v_{g}-v u} d u
$$

where it has been taken into account that $v=\delta \times / A^{*}$, $v_{g}=\aleph_{g} r / A^{*}, d u / d r=1 / r_{g}, d u / d r_{g}=-u / r_{g}$.

If it was obtained $v, v_{g}$ and $d v / d u$ from (8), the equation (21) can be rewritten as:

$$
\frac{d g^{\prime}(u)}{g^{\prime}(u)}=-\frac{4 u^{5}+u^{3}\left(3 x^{2}-2 x-1\right)+u x(9 x+6)-12 x^{2}-4 x}{u(1-u)^{2}\left[u^{3}+u^{2} x(3 x-1)+3 u x^{2}+x(3 x+1)\right]} d u,
$$

and then the Wagner-Vengrenovich distribution (20) will be obtained after integration of the above equation.

The third order polynomial in the denominator of (22) has to be decomposed by $u$ to the simple terms before equation (22) can be integrated.

$$
u^{3}+u^{2} x(3 x-1)+u 3 x^{2}+x(3 x+1)=(u+b)\left(u^{2}+c u+d\right)
$$

where the root of cubic equation (23) will be calculated by Cardano formula:

$$
\begin{gathered}
b=(\mu / 3)-w-v, \\
\mu=3 x^{2}-x, w=\sqrt{-(q / 2)+\sqrt{z}}, v=\sqrt{-(q / 2)-\sqrt{z}}, t=3 x^{2}+x, q=\left(2 \mu^{3} / 27\right)-(\mu s / 3)+t, s=3 x^{2}, \\
z=(p / 3)^{3}+(q / 2)^{3}, p=\left(3 s-\mu^{2}\right) / 3,
\end{gathered}
$$

and the coefficients are:

$$
d=\left(\frac{w+v}{2}\right)^{2}+\left(\frac{w+v}{3}\right) \mu+\left(\frac{\mu}{3}\right)^{2}+\frac{3}{4}(w+v)^{2}, c=\frac{2}{3} \mu+w+v .
$$

With account of (23), after integration of (22) up to the constant $Q$, we can get the Wagner-Vengrenovich distribution [30]:

$$
g^{\prime}(u)=u^{\sigma}(1-u)^{-\alpha}(u+b)^{\beta}\left(u^{2}+c u+d\right)^{\gamma} \exp \left(\frac{\omega}{1-u}\right) \exp \left[\frac{\varepsilon-\gamma c}{\sqrt{d-c^{2} / 4}} \tan ^{-1}\left(\frac{u+c / 2}{\sqrt{d-c^{2} / 4}}\right)\right],
$$

where,

$$
\begin{gathered}
\alpha=\frac{18 x^{2}(b+1)(c+d+1)+11(b c+d)+8(b+c)+14 b d+5}{\left(b^{2}+2 b+1\right)\left(c^{2}+d^{2}+2 c d+2 c+2 d+1\right)} \\
, \beta=\frac{\left(3 b^{3}+9 b+12\right) x^{2}+\left(6 b-2 b^{3}+4\right) x+4 b^{5}-b^{3}}{b\left(b^{2}-b c+d\right)\left(b^{2}+2 b+1\right)}, \\
\sigma=\frac{4 x(3 x+1)}{b d}, \gamma=\frac{\alpha-\sigma-\beta-4}{2}, \\
\omega=-\frac{3}{(b+1)(c+d+1)}, \\
\varepsilon=\sigma(2-b-c)+\alpha(b-1)-\omega+\beta(2-c)+2 \gamma(2-b) .
\end{gathered}
$$

It should be noted that according to (8) and (9), $x$ cannot be equal to 0 and 1 remaining within the range $0<x<1$.
If $x$ is tending to zero $(x \rightarrow 0), \sigma \rightarrow 4, \alpha \rightarrow 5$, $\omega \rightarrow-3, \beta \rightarrow-1, \gamma \rightarrow-1, \varepsilon \rightarrow 0$ and the distribution (26) is up to the constant $Q$ equivalent to the distribution $\mathrm{V}$ [5]

$$
g^{\prime}(u)=u(1-u)^{-5} \exp \left(-\frac{3}{1-u}\right) .
$$

Otherwise, if $x$ is tending to unit $x \rightarrow 1$, for instance, if $x=0.99999: \quad \sigma \approx 4 ; \quad \alpha \approx 2.88889$; $\beta \approx-1.69341 ; \quad \gamma \approx-1.70329 ; \quad \omega \approx-0.29999 ;$ $\varepsilon \approx-0.78535 ; b \approx 1.65063 ; c \approx 0.34937 ; d \approx 2.42332$ the distribution (26) is up to the constant $Q$, equivalent to the distribution $\mathrm{V}$ [12]: 


$$
g^{\prime}(u)=\frac{u^{4} \exp \left(-\frac{0,3}{1-u}\right)}{(1-u)^{2.88889}(u+1,65063)^{1.69341}} \times \frac{\exp \left[-0.123 \cdot \tan ^{-1}(0.64647 u+0.11293)\right]}{\left(u^{2}+0.34937 u+2.42332\right)^{1.70329}},
$$

\section{An evolution of the Wagner- Vengrenovich distribution caused by sliding of the dislocations}

It is considered that the number of germs fixed on the surface of $\mathrm{NC}(Z)$ remains constant throughout the germs development process in case it is controlled by the atoms diffusion along the diffusion tubes. However, the coherent conjugation between $\mathrm{NC}$ and the matrix is getting disturbed as the size (radius) of the crystals is growing. Thus, the fields of elastic stresses near NC will be weakening causing some fading in the germ/dislocation interaction. This leads to unleashing and sliding of the dislocations. This process runs until the sliding dislocation is captured and fixed again by the elastic stresses field near another NC. Therefore, $Z$ is not a constant and is decreasing with increase in the $\mathrm{NC}$ size inversely to $r$ [31]

$$
Z=\frac{Z_{0} \mathrm{q}^{\frac{1}{2}}}{2 \pi r}
$$

where $Z_{0}-$ the initial number of dislocations fixed on the surface of NC with radius $r$.

The flux of matter due to dislocation diffusion $j_{d}(1)$ with account of (29) can be written as

$$
j_{d}=D_{d} 2 \frac{Z_{0} \mathrm{q}^{1 / 2}}{2 \pi r} q\left(\frac{d C}{d R}\right)_{R=r} .
$$

Applying condition (5), the equation for the flux of atoms towards a NC maintained by the dislocation diffusion (30) and Wagner's mechanism of mass transfer (3) and with account of the ratio between the fluxes (7), the formula of the NC growing rate can be represented as

$$
\begin{aligned}
& \frac{d r}{d t}=A^{* *} \frac{1}{r}\left(\frac{x}{1-x} \frac{1}{u^{4}}+1\right)\left(\frac{r}{r_{\mathrm{\kappa}}}-1\right), \\
& \frac{d r}{d t}=B^{* *} \frac{1}{r^{5}}\left(1+\frac{1-x}{x} u^{4}\right)\left(\frac{r}{r_{\mathrm{\kappa}}}-1\right),
\end{aligned}
$$

where

$$
A^{* *}=\sigma v_{m}^{2} C_{\infty} \beta / \mathrm{T} R, B^{* *}=\sigma v_{m}^{2} C_{\infty} Z_{0} q^{3 / 2} D_{d} / 4 \pi^{2} R \mathrm{~T} .
$$

The rate $r_{g_{1}} / r_{k_{1}}$ for the growth mechanism can be found from the above expression (31) (or (32))

$$
\frac{r_{g_{1}}}{r_{k_{1}}}=\frac{2+4 x}{1+4 x}
$$

and then it can be easily transformed into another expressions for temporal dependencies of the NC maximal and critical radiuses

$$
\begin{gathered}
r_{g_{1}}^{2}=2 A^{* *} \frac{t}{1-x^{2}}, r_{k_{1}}^{2}=2 A^{* *} \frac{1+x}{(1-x)(2+x)^{2}} t, \\
r_{g_{1}}=\left(\frac{6 B^{* *}}{(5-3 x)(1-x)} t\right)^{1 / 6}, \\
r_{\mathrm{\kappa}_{1}}=\left(\frac{6 B^{* *}(5-3 x)^{5}}{(6-3 x)^{6}(1-x)} t\right)^{1 / 6} .
\end{gathered}
$$

Thus, the maximal $r_{g_{1}}$ and critical $r_{k_{1}}$ radiuses of the nanocrystal can be found from (34) for the growing conditions controlled by the kinetic coefficient $\beta$ and $x$ as a contribution of the dislocation diffusion.

If $x=0$, the NC growing is completely controlled by the rate of new chemical bonds establishing [5].

$$
r_{g_{1}}^{2}=2 A^{* *} t, \quad r_{k_{1}}^{2}=\frac{1}{2} A^{* *} t, \quad \frac{r_{g_{1}}}{r_{k_{1}}}=2
$$

The above equation (35) corresponds to the temporal dependencies of $r_{g_{1}}$ and $r_{k_{1}}$, under conditions controlled by the dislocation diffusion coefficient $D_{d}$ with $(1-x)$ as a contribution made by that part of the total flux, which is limited by the rate of new chemical bonds formation (chemical reaction) on the surface of $\mathrm{NC}$ (Wagner's mechanism).

If $x=1$, the NC growing is completely controlled by the solute atoms diffusion along the dislocation tubes $[10,12]$

$$
r_{g_{1}}^{6}=\frac{6}{5} B^{* * *} t, \quad r_{\kappa_{1}}^{6}=\left(\frac{5}{6}\right)^{5} B^{* *} t, \quad \frac{r_{g_{1}}}{r_{k_{1}}}=\frac{6}{5} .
$$

Then the size distribution function

$$
g_{1}(u)=Q_{1} \cdot g^{\prime \prime}(u)
$$

with $Q_{1}=3 M /\left(4 \pi \rho \int_{0}^{1} u^{3} g^{\prime \prime}(u) d u\right)$ should be found. In order to do that, $f(r, t)$ and $\&$ should be substituted in the continuity equation (4) with their corresponding values from (16) and (31) (or (32)). Then the variables can be separated through transition from differentiation by $r$ and $t$ to differentiation by $u$ :

$$
\frac{d g^{\prime \prime}(u)}{g^{\prime \prime}(u)}=-\frac{4 v_{g}+\frac{v}{u^{2}}-\frac{1}{u} \frac{d v}{d u}}{w v_{g}-\frac{v}{u}} d u,
$$

and taking into account $v=\phi_{1} / A^{* *}$, 


$$
\frac{d g^{\prime \prime}(u)}{g^{\prime \prime}(u)}=-\frac{4 u^{6}+u^{4}\left(4 x^{2}-3 x-1\right)+u\left(16 x^{2}+8 x\right)-\left(20 x^{2}+5 x\right)}{u(1-u)^{2}\left(u^{4}+u^{3}\left(4 x^{2}-2 x\right)+u^{2}\left(4 x^{2}-x\right)+4 u x^{2}+\left(4 x^{2}+x\right)\right)} d u .
$$

The fourth order polynomial in denominator of (40) should be decomposed to simple terms in order integrate this equation. So, the polynomial can be represented as

$$
\left(u^{4}+u^{3}\left(4 x^{2}-2 x\right)+u^{2}\left(4 x^{2}-x\right)+4 u x^{2}+\left(4 x^{2}+x\right)\right)=\left(u^{2}+a u+d\right)\left(u^{2}+b u+p\right),
$$

or

$$
\left(u^{2}+a u+d\right)\left(u^{2}+b u+p\right)=u^{4}+(a+b) u^{3}+(a b+d+p) u^{2}+(a p+b d) u+d p
$$

Let us transform (42) into

$$
\left.\begin{array}{rl}
u^{4}+(a+b) u^{3}+(a b+d+p) & u^{2}+(a p+b d) u+d p=A^{\prime} u^{3}+B^{\prime} u^{2}+E^{\prime} u+D^{\prime}, \\
A^{\prime} & =(a+b) \\
B^{\prime} & =(a b+d+p) \\
E^{\prime} & =(a p+b d) \\
D^{\prime} & =d p
\end{array}\right\},
$$

where,

This way, a system of equations is obtained and the following variables can be determined

$$
\begin{gathered}
a=\frac{L+n}{2}, b=\frac{L-n}{2}, d=\frac{E^{\prime}+m}{2 b}, p=\frac{E^{\prime}-m}{2 a}, L=4 x^{2}-2 x, E^{\prime}=4 x^{2}, m=\left(\left(L^{2}-n^{2}\right) \mathrm{M}-2 L E^{\prime}\right) /(2(a-b)), \\
n \geq \sqrt{L^{2}-4 H+8 \sqrt{D^{\prime}}}, \quad \mathrm{M} \geq 2 \sqrt{D^{\prime}}, D^{\prime}=4 x^{2}+x, H=34 x^{2}-x .
\end{gathered}
$$

The expression $2 E^{\prime}=L \mathrm{M}-n \sqrt{\mathrm{M}^{2}-4 D^{\prime}}$ can be used for verification.

Taking into account the above expression, (40) can be represented as:

$$
\frac{d g^{\prime \prime}(u)}{g^{\prime \prime}(u)}=-\frac{4 u^{6}+u^{4}\left(4 x^{2}-3 x-1\right)+u\left(16 x^{2}+8 x\right)-\left(20 x^{2}+5 x\right)}{u(1-u)^{2}\left(u^{2}+a u+d\right)\left(u^{2}+b u+p\right)} d u .
$$

Let us transform (45) into a sum of the simple elementary fractions in order to complete its integration

$$
\begin{gathered}
\frac{d g^{\prime \prime}(u)}{g^{\prime \prime}(u)}=-\frac{4 u^{6}+u^{4}\left(4 x^{2}-3 x-1\right)+u\left(16 x^{2}+8 x\right)-\left(20 x^{2}+5 x\right)}{u(1-u)^{2}\left(u^{2}+a u+d\right)\left(u^{2}+b u+p\right)} d u= \\
=\frac{A \cdot d u}{u}+\frac{B \cdot d u}{1-u}+\frac{C \cdot d u}{(1-u)^{2}}+\frac{(D u+E) \cdot d u}{u^{2}+a u+d}+\frac{(F u+G) \cdot d u}{u^{2}+b u+p},
\end{gathered}
$$

where an undefined coefficients method can be employed to find the coefficients $A, B, C, D, E, F, G$. A system of equations will be obtained after equating the same $u$ exponent coefficients in the left and right part numerators:

$$
\left\{\begin{array}{l}
A-B+D+F=-4 \\
A(a+b-2)+B(1-b-a)+C+D(b-2)+E+F(a-2)+G=0 \\
A(-2 a+a b-2 b+1+p+d)+B(-a b+b-p+a-d)+C(b+a)+ \\
+D(p+1-2 b)+E(b-2)+F(d+1-2 a)+G(a-2)=-4 x^{2}+3 x+1 \\
A(-2 p-2 a b-2 d+a p+a+d b+b)+B(p-a p+d-d b+a b)+ \\
+C(p+a b+d)+D(b-2 p)+E(p+1-2 b)+F(a-2 d)+G(d+1-2 a)=0 . \\
A(d-2 d b+p+a b+d p-2 a p)+B(a p+d b-d p)+C(a p+d b)+ \\
+D p+E(b-2 p)+F d+G(a-2 d)=0 \\
A(a p-2 d p+d b)+B d p+C d p+E p+G p=-\left(16 x^{2}+8 x\right) \\
A d p=\left(20 x^{2}+5 x\right) .
\end{array}\right.
$$

An analytical function for the size distribution will be obtained by integration of (46) up to the constant $Q$ for any $0 \leq x \leq 1$ :

$$
g^{\prime \prime}(u)=\frac{u^{5}\left(u^{2}+a u+d\right)^{D / 2}\left(u^{2}+b u+p\right)^{F / 2}}{(1-u)^{B}} \exp \left(\frac{C}{1-u}\right) \times
$$




$$
\times \exp \left(\frac{E-\frac{D a}{2}}{\sqrt{d-\frac{a^{2}}{4}}} \tan ^{-1} \frac{u+\frac{a}{2}}{\sqrt{d-\frac{a^{2}}{4}}}\right) \times \exp \left(\frac{G-\frac{F b}{2}}{\sqrt{p-\frac{b^{2}}{4}}} \tan ^{-1} \frac{u+\frac{b}{2}}{\sqrt{p-\frac{b^{2}}{4}}}\right),
$$

If $x$ is tending to zero $(x \rightarrow 0), a \rightarrow 0, d \rightarrow 0, b \rightarrow 0, p \rightarrow 0, B \approx-5, D \approx-2, F \approx-2, C \approx-3, E \approx 0$, $G \approx 0$ and the distribution (48) matches the distribution W [5] up to the constant $Q$

$$
g^{\prime \prime}(u)=u(1-u)^{-5} \exp \left(-\frac{3}{1-u}\right) .
$$

If $x$ is tending to unit $x \rightarrow 1$, for instance $x=0.99999, a \approx 2.57753, d \approx 2.39425, b \approx-0.57753, p \approx 2.08834$, $B \approx 2.73445, D \approx-3.12433, F \approx-3.14119, C \approx-0.20008, E \approx-4.05171, G \approx 0.74734$ and the distribution (49) matches the one reported in [31] up to the constant $Q$

$$
\begin{gathered}
g^{\prime \prime}(u)=\frac{u^{5}\left(u^{2}+2.578 u+2.394\right)^{-1.562}\left(u^{2}-0.578 u+2.088\right)^{-1.571}}{(1-u)^{2,734}} \times \\
\times \exp \left(-\frac{0.2}{1-u}\right) \exp \left(-0.277 \tan ^{-1} \frac{u+1.289}{0.856}\right) \exp \left(-0.11 \tan ^{-1} \frac{u-0.289}{1.416}\right) .
\end{gathered}
$$

\section{Ostwald ripening of the reinforcing phase particles controlled by the matrix diffusion, the diffusion along dislocations and the rate of the interphase atom transfer. Rate of growth}

The diffusion mechanism of the growing during OR was proposed by Lifschitz and Slezov in their wellknown paper [3]. That is why a term "LSW theory" is used traditionally to refer to the theory that represents growing of particles during OR either according to the diffusion or to the Wagner's mechanism.

It is traditionally considered that the rate of interphase transfer of atoms is comparatively high [3236] making the diffusion approach to the nanoclusters (CL) growing more popular and leaving the Wagner's mechanisms beyond regular consideration. This approach was used in the majority of theoretical works dealing with OR while their results were in good agreement with experiments.

It should also be noted that a meaning of the term "CL" in many cases is much wider: depending on the particles' size, they can be referred to as CL, nanoclusters or nanocrystals (NC). The Wagner's mechanism is sometimes considered as a chemical reaction running on the surface of $\mathrm{NC}$ and resulting in formation of new interatomic bonds.

Recently, some deviations from the classical LSW theory were reported in some works dealing with advances in nanotechnologies. For instance, it has been shown by Sarma and coworkers [37-39] that the experimental particles size distribution did not match the theoretical LS pattern while the dependence $\langle r\rangle \sim t^{1 / 3}$ was not observed either. It means that the diffusion mechanism does not control growing of nanoparticles when the synthesis is performed by the chemical methods.

In case of the quantum dots (QD) containing nanocomposites and heterosystems, the diffusion mechanism of growing control does not act either. Neither LS nor W theoretical patterns can describe these experimental data. Instead, the generalized LifschitzSlezov-Wagner (GDLSW) distribution can be used in case of 3-D systems while 2-D systems can be adequately described through the generalized Chakraverty-Wagner (ChW) approach [25, 27, 28, 41, 43, 45].

As noted above, the modified LSW theory was constructed for the case when the particles growth is controlled by the diffusion (bulk or surface), the rate of atoms transfer across the interphase or the rate of chemical reaction simultaneously. However, extra adaptations should be made in order to apply this theory to the metal systems where the growth can be controlled by the dislocation diffusion, which runs along separate dislocations or dislocation tubes.

When this mechanism is involved, the flux of atoms along the dislocations $j_{d}$ can be represented by (1).

When the growth occurs under the mixed dislocation-matrix diffusion, this flux can be written as

$$
j^{\prime}=j_{v}+j_{d} \text {, }
$$

where the matrix diffusion-controlled flux of atoms can be characterized through the bulk diffusion coefficient $D_{v}$ and written as $[3,4]$

$$
j_{v}=D_{v} 4 \pi r^{2} \frac{\langle C\rangle-C_{r}}{r} .
$$

In this case, the total flux of the atoms participating in formation of new bonds can be written in this form:

$$
j=j^{\prime}+j_{i}=j_{v}+j_{d}+j_{i} .
$$

In the framework of the Lifschitz-Slezov diffusion mechanism of growth $[3,4]$, it is a priori considered that all atoms transported towards CL by the bulk diffusion will be bonded with the particle surface. In other words, the rate of new interatomic bonds formation is considered high and the structure of the CL material is quickly developing. In many case this is correct and 
experimental data prove this assumption. However, this mechanism can act only if the rate of new interatomic bonds formation is much higher than the rate of diffusion (physical or chemical). If this is not so, only insignificant number of the atoms delivered to the surface will be involved in formation of new interatomic bonds or take part in the chemical transformation. The majority of atoms will be blocked and accumulated near CL surface.

Then their concentration should be considered. In general, it is unknown $\left(C_{x}\right)$. However, as a first approximation and to avoid dynamic instability, it can be taken as equal to the mean concentration of atoms dissolved in the matrix $C_{x}=\langle C\rangle$.

A particle fixed in the array of atoms blocked near CL can eventually be moved to the surface by thermal movement. The flux of such particles per unit of time $j_{d}$ will be proportional to the blocked atoms concentration $\langle C\rangle, \mathrm{CL}$ surface area $\left(4 \pi r^{2}\right)$ (taking that it is a sphere) and the proportionality coefficient $\beta$ known as the kinetic coefficient

$$
j_{1}=\beta 4 \pi r^{2}\langle C\rangle \text {. }
$$

Since the rate of new interatomic bonds formation is comparatively low, not all particles among those delivered by the flux $j_{1}$ will be involved in the process and the reversed flux of particles directed away from the surface $j_{2}$ can be represented as

$$
j_{2}=\beta 4 \pi r^{2} C_{r},
$$

where $C_{r}$ - the surface or near-surface concentration of atoms. A difference between these two fluxes shows a number of atoms involved in formation of new interatomic bonds per unit of time $j_{i}=j_{1}-j_{2}=\beta 4 \pi r^{2}\left(\langle C\rangle-C_{r}\right)$.

Flux $j_{i}$ is referred to as kinetic unlike the diffusion flux $j^{\prime}(3)$.

Therefore, two different fluxes: diffusion $j^{\prime}$ and kinetic $j_{i}$ are bringing the atoms to take part in formation of new interatomic bonds (53). However, a contribution of each flux is unknown. Let us denote the contribution of $j_{v}$ as $x$ and the contribution of $j_{d}$ as $y$ while $j$ will be the total flux

$$
x=\frac{j_{v}}{j}, \quad y=\frac{j_{d}}{j},
$$

then the kinetic flux contribution can be written as

$$
1-x-y=\frac{j_{i}}{j} \text {. }
$$

Taking into account that $j^{\prime}=x j+y j$ and $j_{i}=(1-x-y) j$, the ratio between the diffusion and kinetic fluxes will be

$$
\frac{j^{\prime}}{j_{i}}=\frac{x+y}{1-x-y} .
$$

If $x=0$ and $y=0$, as seen from (53), the total flux can be written as $j=j_{i}$. This means that the rate of new interatomic bonds formation controls the growth of $\mathrm{CL}$ or, in other words, this case represents the extreme Wagner's mechanism and the particles size distribution should correspond to the theoretical $\mathrm{W}$ pattern.

If $x=1$ and $y=0$, then $j=j_{v}$ : the growth of CL is controlled by the matrix or bulk diffusion - this is the extreme diffusion mechanism of growth discussed in [3]. In this case, the size distribution corresponds to the pattern LS.

Finally, if $x=0$ and $y=1$, then $j=j_{d}$. The particles growth is controlled by the dislocation diffusion while the size distribution will correspond to the pattern discussed in [12].

All three parts of (53) will be contributing in the total flux $j$ if the $x$ and $y$ values are ranged between $0 \leq x, y \leq 1$. Let us find an analytical form of the size distribution function for this case.

The continuity equation (4) can be used to determine this function $f(r, t)$. Using the condition (5), we can represent the flux $j$ through the explicit form of (53)

$$
\begin{aligned}
& j=D_{v} 4 \pi r^{2} \frac{\langle C\rangle-C_{r}}{r}+D_{d} 2 Z q \frac{\langle C\rangle-C_{r}}{r}+ \\
& +\beta 4 \pi r^{2}\left(\langle C\rangle-C_{r}\right)
\end{aligned}
$$

After substituting (54) into (5) and performing some simple transformations, the growth rate equation can be obtained in the following three forms

$$
\frac{d r}{d t}=\frac{A}{r}\left(1+\frac{x}{1-x-y} \frac{r_{g}}{r}+\frac{y}{1-x-y} \frac{r_{g}^{3}}{r^{3}}\right)\left(\frac{r}{r_{k}}-1\right) \text {, }
$$

where $A=\frac{2 C_{\infty} \beta \sigma v_{m}^{2}}{k T}, \sigma-$ a specific value of the surface energy, $k$ - the Boltzmann's constant;

$$
\frac{d r}{d t}=\frac{B}{r^{2}}\left(1+\frac{1-x-y}{x} \frac{r}{r_{g}}+\frac{y}{x} \frac{r_{g}^{2}}{r^{2}}\right)\left(\frac{r}{r_{k}}-1\right),
$$

where $B=\frac{2 C_{\infty} D_{v} \sigma v_{m}^{2}}{k T}$;

$$
\frac{d r}{d t}=\frac{C}{r^{4}}\left(1+\frac{x}{y} \frac{r^{2}}{r_{g}^{2}}+\frac{1-x-y}{y} \frac{r^{3}}{r_{g}^{3}}\right)\left(\frac{r}{r_{k}}-1\right),
$$

where $C=\frac{C_{\infty} D_{d} \sigma v_{m}^{2} Z q}{\pi k T}$.

The equation (60) is related to the CL growth rate controlled mainly by the rate of interatomic bonds establishing where $x$ is a contribution of the matrix diffusion and $y$ - a contribution of the diffusion running along the dislocations.

The equation (61) corresponds to the case when the CL growth rate is controlled mainly by the flux of atoms maintained by the matrix diffusion. Here $y$ means a contribution of the flux of atoms running along the dislocations while the kinetic flux contribution corresponds to $1-x-y$.

Similarly, (62) corresponds to the CL growth governed by the dislocation diffusion with $y$ as a contribution of the matrix diffusion and $1-x-y$ the kinetic flux contribution. 


\section{Temporal dependencies for the maximal $r_{g}$ and critical $r_{k}$ (or mean $\langle r\rangle)$ sizes of $\mathbf{C L}$}

The temporal dependencies for $r_{g}$ can be determined by integration of (60)-(62) and taking $r=r_{g}$. However, these operations are possible only if the value of ratio $r_{g} / r_{k}$ is known. According to [32], this ratio can be found from the specific growth rate equation $\delta / r$ if its maximum point derivation is zero $-\frac{d}{d r}\left(\frac{\delta}{r}\right)_{r=r_{g}}=0$. Performing these transformations and using for example (60), one can obtain

$$
\frac{r_{g}}{r_{k}}=\frac{x+3 y+2}{x+3 y+1} \text {. }
$$

Having found the ratio $r_{g} / r_{k}$, we can get after integration of (60)-(62):

for the prevalent Wagner's mechanism

$$
r_{g}^{2}=\frac{2 A}{(1-x-y)(x+3 y+1)} t
$$

for the prevalent diffusion mechanism

$$
r_{g}^{3}=\frac{3 B}{x(x+3 y+1)} t
$$

and for the prevalent diffusion along the dislocation mechanism

$$
r_{g}^{5}=\frac{5 C}{y(x+3 y+1)} t .
$$

Then the temporal dependencies of $r_{k}$ can be found from (63) using (64)-(68)

$$
\begin{gathered}
r_{k}^{2}=\frac{2 A(x+3 y+1)}{(x+3 y+2)^{2}(1-x-y)} t, \\
r_{k}^{3}=\frac{3 B(x+3 y+1)^{2}}{x(x+3 y+2)^{3}} t, \\
r_{k}^{5}=\frac{5 C(x+3 y+1)}{y(x+3 y+2)^{5}} t .
\end{gathered}
$$

Equations (64) - (69) can further be used to determine the values corresponding to the following extreme approaches:
Wagner's mechanism $(x=0, y=0)$

$$
r_{g}^{2}=2 A t, \quad r_{k}^{2}=\frac{A}{2} t,[8]
$$

diffusion mechanism $(x=1, y=0)$

$$
r_{g}^{3}=\frac{3}{2} B t, r_{k}^{3}=\frac{4}{9} B t \quad[9] ;
$$

dislocation mechanism $(x=0, y=1)$

$$
r_{g}^{5}=\frac{5}{4} C t, r_{k}^{5}=\frac{4^{4}}{5^{4}} C t[31] .
$$

\section{Size distribution of the nanoparticles (clusters)}

The CL size distribution function $f(r, t)$ can be obtained from (4) using one of the growth rate equations, i.e. (60).

$$
f(r, t)=\frac{1}{r_{g}^{4}} g(u)
$$

where $g(u)$ is the relative NP size distribution function

$$
\left(g(u)=Q g^{\prime}(u)\right) \text {. }
$$

However, $g^{\prime}(u)$ should be found in order to determine $g(u)$. This can be realized by substitution of $f(r, t)$ in the continuity equation with its value from (73) and substitution of $\delta$ with its value from (60). Then (4) should be differentiated by $u$ instead of differentiation by $r$ and $t$. Then the variables can be separated in (4) and it will be written as

$$
\frac{d g^{\prime}(u)}{g^{\prime}(u)}=-\frac{4 v_{g} u^{2}-\frac{d v}{d u} u+v}{u^{3} v_{g}-v u} d u,
$$

where the dimensionless growth rate

$$
\begin{aligned}
& v=\frac{r}{A} \frac{d r}{d t}=\left(1+\frac{x}{1-x-y} \frac{1}{u}+\frac{y}{1-x-y} \frac{1}{u^{3}}\right) \times\left(\frac{x+3 y+2}{x+3 y+1} u-1\right) \\
& \text { and } \quad v_{g}=\frac{r_{g}}{A} \frac{d r_{g}}{d t}=\frac{1}{(1-x-y)(x+3 y+1)} .
\end{aligned}
$$

Substituting $v, \frac{d v}{d u}$ and $v_{g}$ into (74), this equation will be transformed into:

$$
\frac{d g^{\prime}(u)}{g^{\prime}(u)}=-\frac{4 u^{5}+u^{3}\left(-2 y^{2}+7 y x+2 x^{2}+3 y^{2}+2 x-1\right)-u^{2}\left(6 y x+2 x^{2}+2 x\right)+3 u\left(3 y^{2}+2 y+y x\right)-4 y(3 y+y x+1)}{u(1-u)^{2}\left(u^{3}+u^{2}\left(4 y x-y+x+3 y^{2}+x^{2}\right)+u\left(3 y^{2}+y x\right)+y(3 y+x+1)\right)} d u
$$

The size distribution of CL can be obtained after decomposition of the third order polynomial in the denominator of (75) followed by integration of $g^{\prime}(u)$ up to the constant $Q$

$$
g^{\prime}(u)=u^{\sigma}(1-u)^{-\alpha}(u+b)^{\beta}\left(u^{2}+c u+d\right)^{\gamma} \times \exp \left(\frac{\omega}{1-u}\right) \exp \left(\frac{\varepsilon-\gamma c}{\sqrt{d-\frac{c^{2}}{4}}} \tan ^{-1} \frac{u+\frac{c}{2}}{\sqrt{d-\frac{c^{2}}{4}}}\right),
$$


the values of the coefficients $b, c, d, \sigma, \alpha, \beta, \gamma, \varepsilon$ and the method of their calculation are given in Appendix 1. After finding $g^{\prime}(u)$, the values of $Q, g(u)$ and $f(r, t)$ can also be obtained.

The equation (76) remains valid for the general case when all three fluxes $j_{v}, j_{d}$ and $j_{i}$, are contributing into the growth (dissolution) process, i.e. $0 \leq x, y \leq 1$. Provided that (76) is correct, the distributions W, LS and the one reported in [12] should be obtained from this formula as the extreme cases.

Actually, if the Wagner's mechanism is acting ( $x \rightarrow 0$ and $y \rightarrow 0$ ), the distribution (76) matches the $\mathrm{W}$ distribution up to the constant $Q$

$$
g^{\prime}(u)=u(1-u)^{-5} \exp \left(-\frac{3}{1-u}\right) .
$$

When the extreme diffusion mechanism is acting $(x \rightarrow 1, y \rightarrow 0)$, the distribution (75) matches the LS distribution up to a constant

$$
g^{\prime}(u)=u^{2}(1-u)^{-11 / 3}(u+2)^{-7 / 3} \exp \left(-\frac{1}{1-u}\right) \text {. }
$$

Finally, if $x \rightarrow 1, y \rightarrow 0$ and the growth is controlled by the diffusion running along the dislocation tubes, (76) matches the distribution reported by Vengrenovich in [12], section V

$$
g^{\prime}(u)=\frac{u^{4} \exp \left(-\frac{0.3}{1-u}\right) \exp \left(-0.123 \tan ^{-1} \frac{u+\frac{c}{2}}{\sqrt{d-\frac{c^{2}}{4}}}\right)}{(1-u)^{\alpha}(u+b)^{\beta}\left(u^{2}+c u+d\right)^{\gamma}} .
$$

\section{Discussion}

The Wagner-Vengrenovich theoretical patterns (20) are shown in Fig. $1 a$ for various values of $x$ taken with step $\Delta x=0.1$.

Separate patterns for $x=0$ and $x=0.1$ are given as an embedding since they cannot be adequately represented in the main scale of Fig. 1a. It can be noted that the $\mathrm{W}$ distribution (27) is smoothly transforming into the $\mathrm{V}$ shape (28).

Same curves being normalized by their maximums are shown in Fig $1 b$. These normalized functions are more suitable for comparison with the corresponding normalized experimental histograms.

In order to do that, the experimental histograms must be normalized in the same way as the theoretical patterns. The scale of the horizontal axis should be changed to the conventional units $u=r / r_{g}=d / d_{g}$, where $r(d)$ is a radius (diameter) of NC and $r_{g}\left(d_{g}\right)$ is its maximal value taken from the series of histograms.
Using this rescaling, the relative (normalized) diameter $u$ will be kept within 0 and 1 .

The vertical axis represents a number of particles per unit of diameter taken within some range $\Delta d$. This axis can be normalized by the maximum of histogram in the similar way. This way, the histograms will be normalized by unit along both axes. Due to this operation, the experimental histograms and theoretical curves can be led to a common scale and then compared to assess a qualitative similarity between them. The initial and central curvature moments should be compared for the theoretical and experimental data arrays to evaluate a degree of their quantitative similarity.

A comparison between the normalized experimental histograms and normalized theoretical curves calculated by (20) is shown in Fig. 2 for different values of $x$. The experimental data were obtained for the size distribution of $\mathrm{Al}_{3} \mathrm{Sc} \mathrm{NC}$ in the binary alloys $\mathrm{Al}-\mathrm{Sc}(0.12$ atom \% of $\mathrm{Sc})$ after keeping them at $350{ }^{\circ} \mathrm{C}$ during: $\left.\left.a\right)-2 ; b\right)-5$; c) $-72 ; d)-104 ; e)-168$ hours [45].

The dotted lines correspond to the $\mathrm{W}(x=0)$ and $\mathrm{V}$ $(x=1)$ distributions.

Besides, for comparison purposes, the LS distribution [78] calculated up to the integration constant is also shown as a separate dotted line.

The solid line represents the Wagner-Vengrenovich distribution (20) for the corresponding values of $x$. As seen from the Fig. 2, neither $\mathrm{W}$ nor $\mathrm{V}$ distributions are in agreement with the experimental histograms. The LS distribution seems more suitable for that and, at some values of $x$, the Wagner-Vengrenovich distribution can be used as well. However, it can be noted that the latter distribution (20) is in a better agreement with the experimental data than the Lifschitz-Slezov approach.

A distribution (38) is represented by the curves in Fig. $3 a$. This case shows a system with a variable $Z$ that is decreasing with increase in the NC size reversely to $r$. The curves are calculated for different values of $x$ taken with a step $\Delta x=0.1$. The curves corresponding to $x=0$, $x=0.1$ and $x=0.2$ are shown in a separate embedding since they cannot be adequately presented in the main figure scale.

Same curves are presented in Fig. $3 b$ after normalization by their maximums.

A comparison between the experimental histograms (Fig. 2) and the theoretical distributions (38) are shown in Fig. 4 for various values of $x$. The dotted lines mean the $\mathrm{W}$ distribution $(x=0)$, distribution $(38)(x=1)$ and LS distribution.

It can be seen that the theoretical data are in good agreement with the distribution (38) at $x=0.3$ and $x=0.4$. However, it can be concluded that an agreement between the Wagner-Vengrenovich distribution (20) and experimental data is better than that for the distribution 

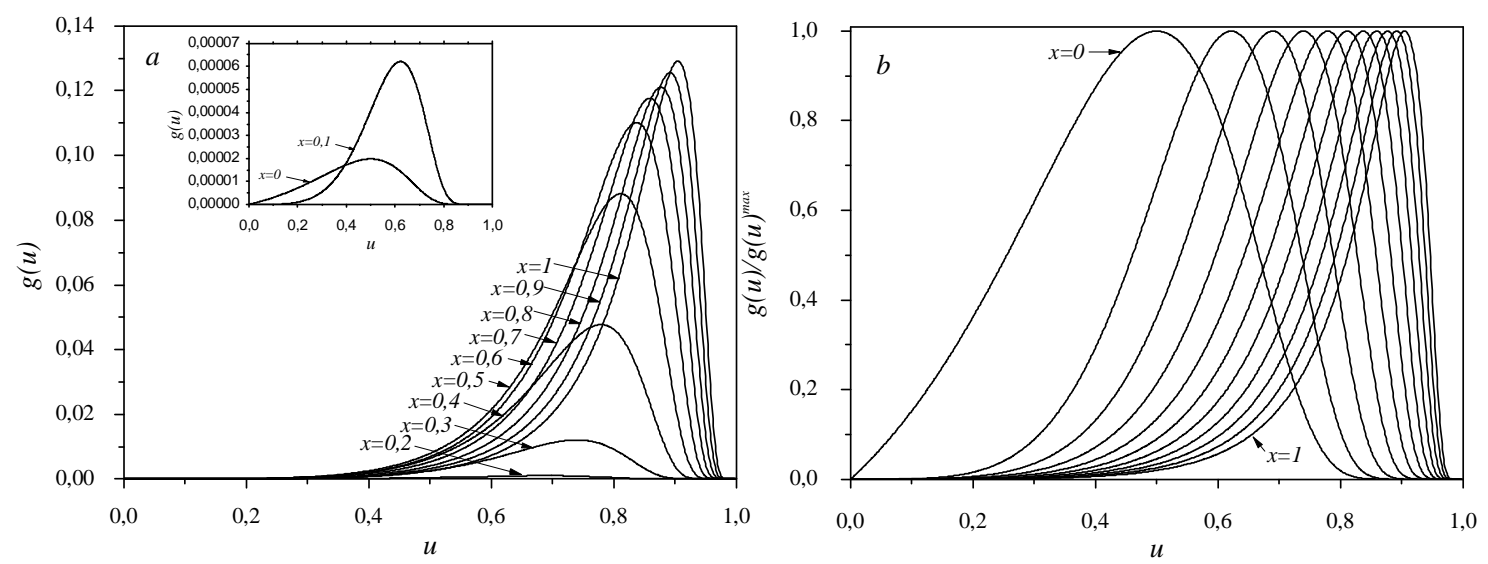

Fig. 1. The Wagner-Vengrenovich distribution curves (20) calculated with the step $\Delta x=0.1-$ (a). Same curves but normalized by their respecting maximums - (b).
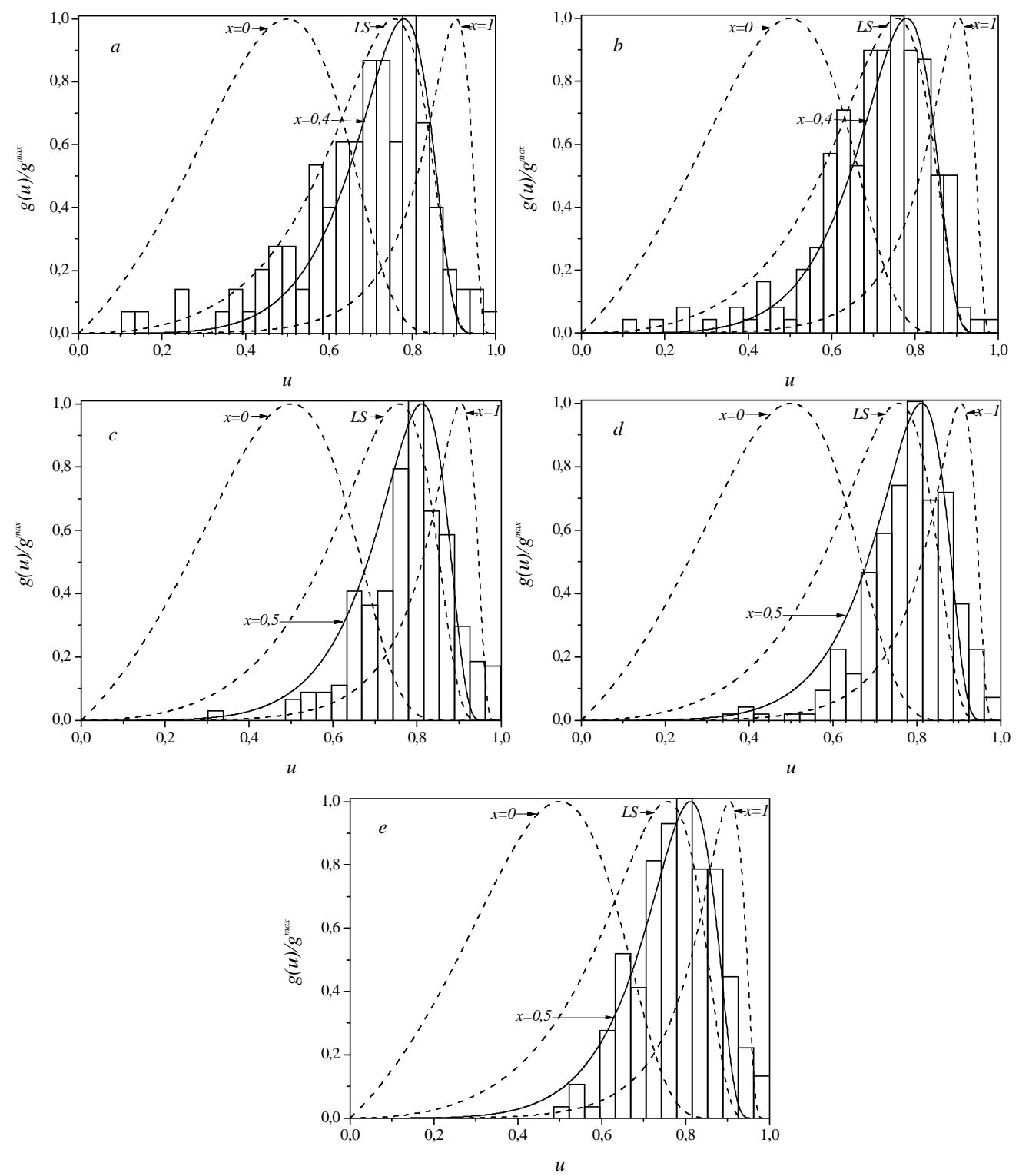

Fig. 2. A comparison of the experimental histograms of the $\mathrm{NC}^{-1} \mathrm{Sc}_{3} \mathrm{Sc}$ size distribution [45] with the WagnerVengrenovich distribution (20) (solid line), for themal treatment of Al-Sc alloy $\left(0.12\right.$ atom \% Sc ) at $350^{\circ} \mathrm{C}$ during: a) - 2; b) - 5; c) - 72; d) - 104; e) - 168 hours. 
R.D. Vengrenovich, B.V. Ivanskii, M.O. Stasyk, S.V. Yarema, A.V. Moskaliuk, I.I. Panko, V.I. Kryvetskyi, I.V. Fesiv

(38) in case $Z \neq$ const .

A kinetics of OR of nanodisperse phases of the metal alloys becomes much more complicated if all three mechanisms are involved in the mass transfer from the matrix towards a NP or back (Fig. 2), (the one mechanism depends on the bulk diffusion coefficient $D_{v}$, another one - on the coefficient of diffusion running along the dislocation tubes $D_{d}$ and the last one - on the rate of atoms transportation across the interphase (kinetic
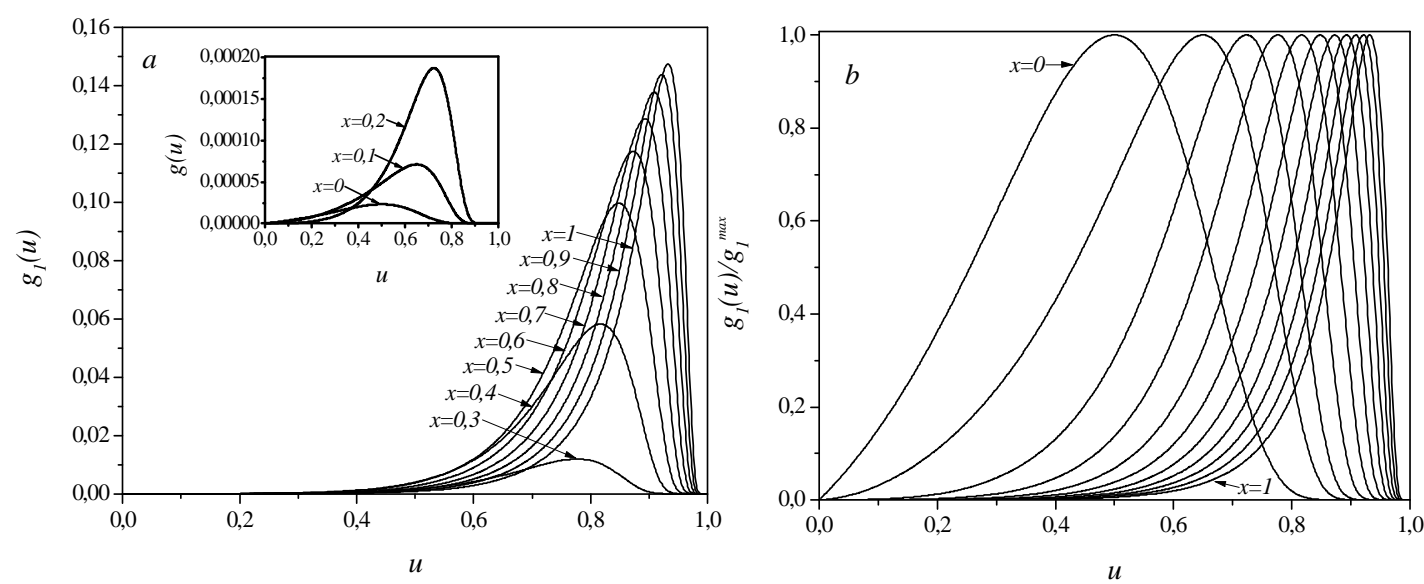

Fig. 3. The distribution (38) curves calculated with the step $\Delta x=0.1-$ (a). Same but normalized curves - (b).
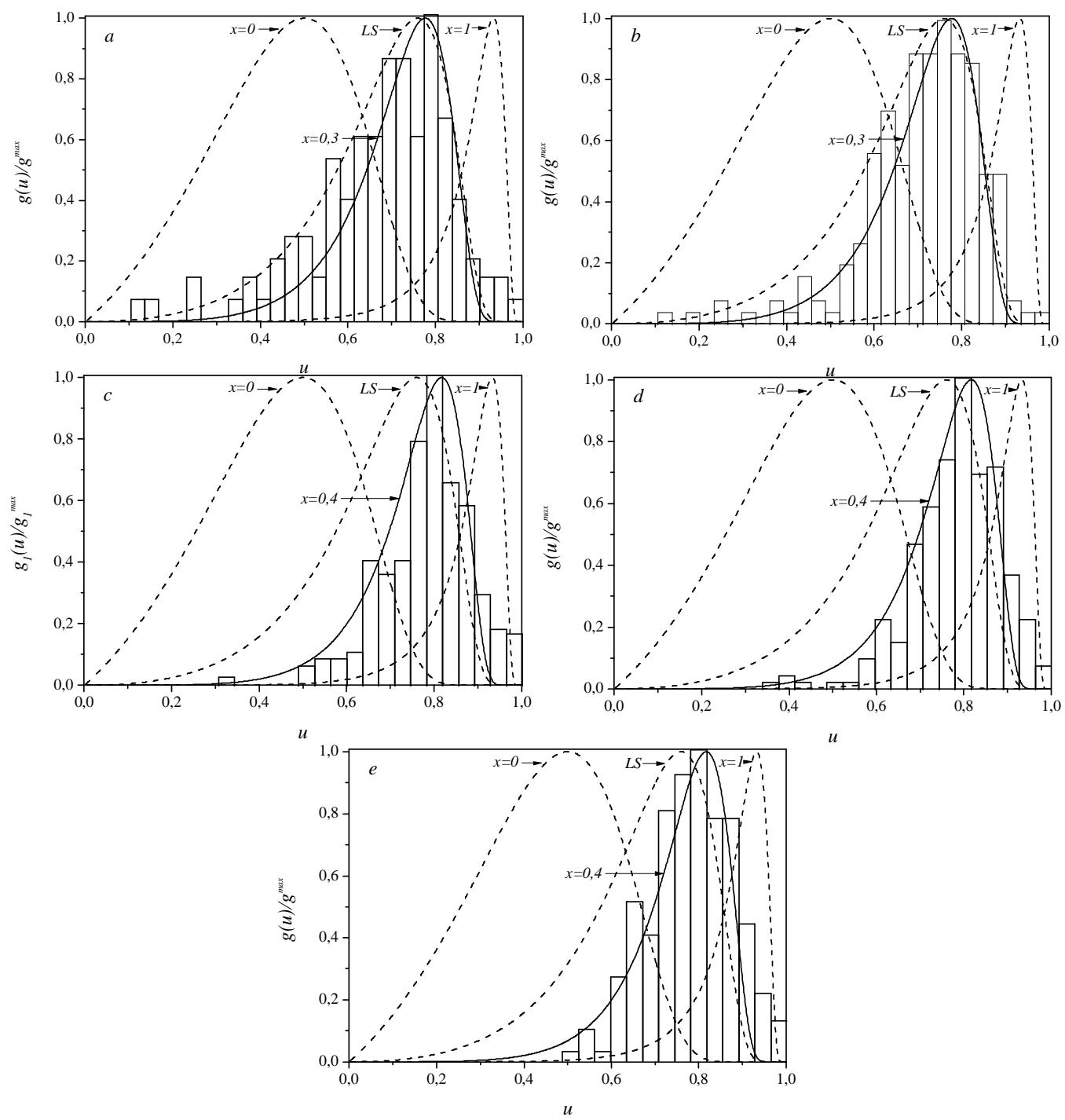

Fig. 4. A comparison between the experimental histograms shown in Fig. 2 with the (38) distribution (solid line). 

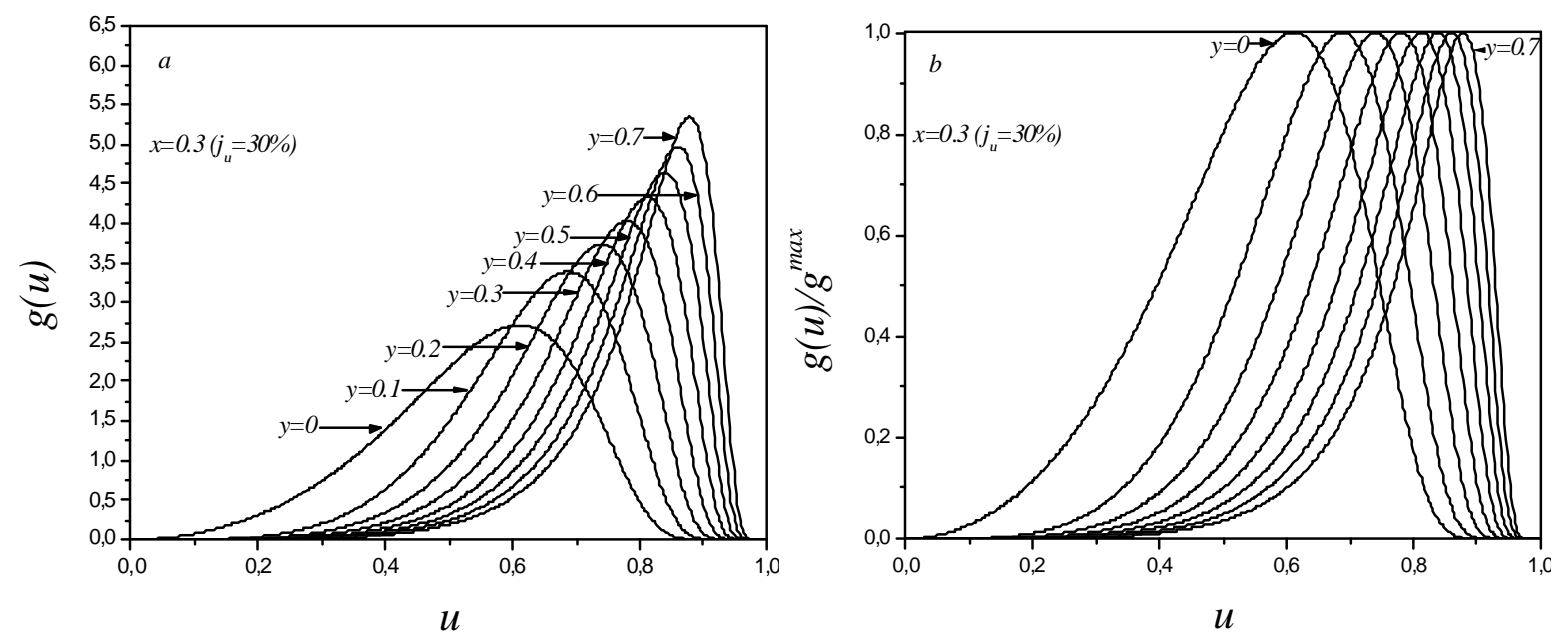

Fig. 5. The distribution $\left(73^{*}\right)$ : a) - depending on y; b) - Same curves $\left(73^{*}\right)$ but normalized by their maximums.
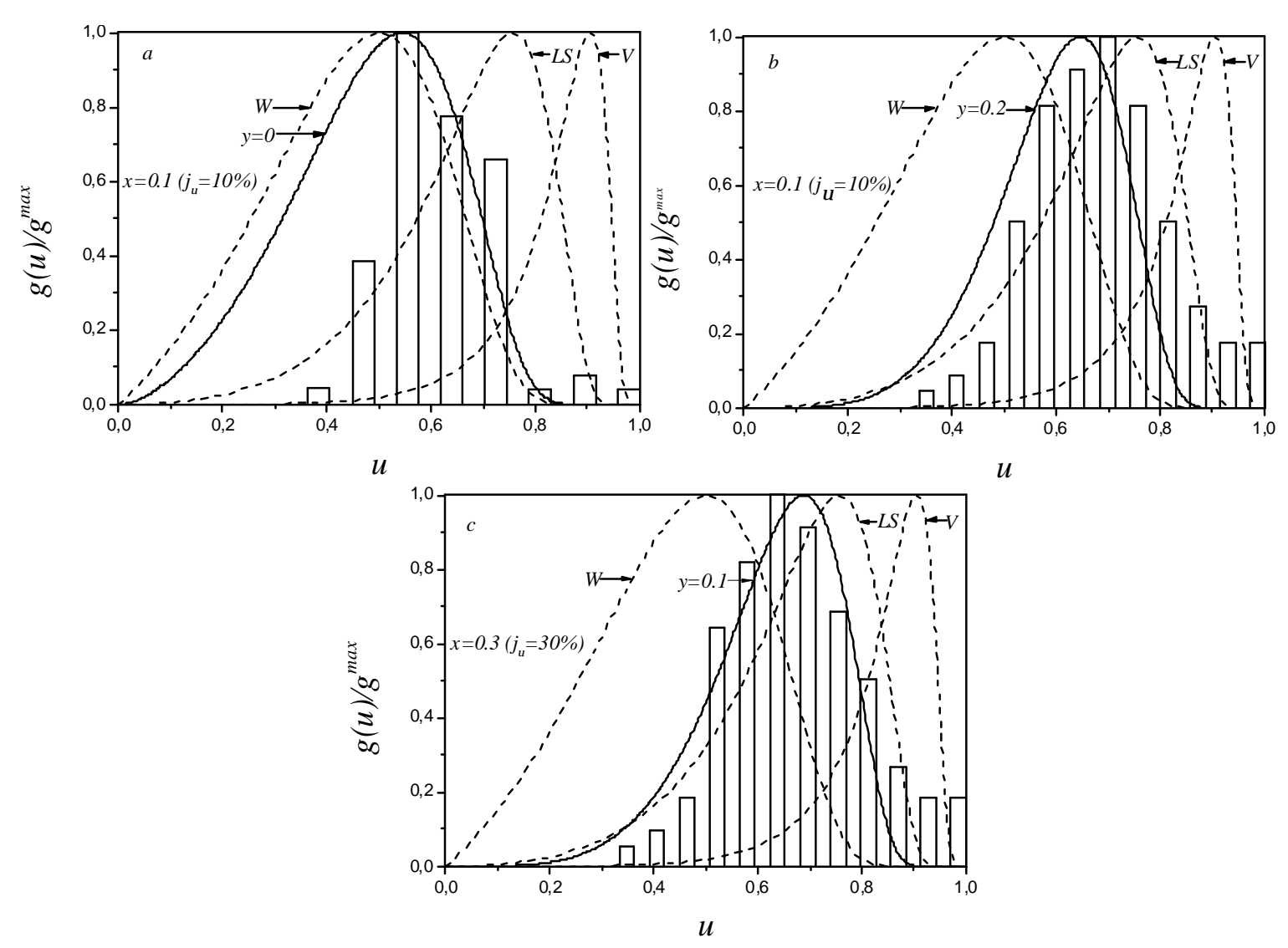

Fig. 6. A comparison between the curve $\left(73^{*}\right)$ with the experimental histograms of the $\mathrm{NC} \mathrm{Ni}_{3} \mathrm{Al}$ size distributions in the alloys $\mathrm{CuNi}_{15} \mathrm{Al}_{5}$ during their thermal treatment at $450{ }^{\circ} \mathrm{C}$ during a) -24 ; b) -96 ;

$$
\text { c) }-380 \text { hours [47]. }
$$

coefficient $\beta$ )). In this case, all kinetic characteristics of the nanodisperse systems including the NC size distribution function become dependent on two parameters $-x$ and $y$ (see $\left.(61)-(69),\left(73^{*}\right),(76)\right)$. A series of the theoretical curves calculated by the formula $g(u)=Q g^{\prime}(u)$ with $g^{\prime}(u)$ taken from (76) is shown in Fig. $5 a$ and $b$ for a fixed value of $x$ and various values of $y$. The value $x=0.3$ means that the matrix diffusion flux contributes $30 \%$ to the total flux $j$. The range of $y$ changes is limited by the conditions

$$
\left\{\begin{array}{l}
0 \leq x, y \leq 1 \\
0 \leq x+y \leq 1
\end{array}\right.
$$

meaning that if $x=0.3, y$ would change within $[0 \div 0.7]$. 

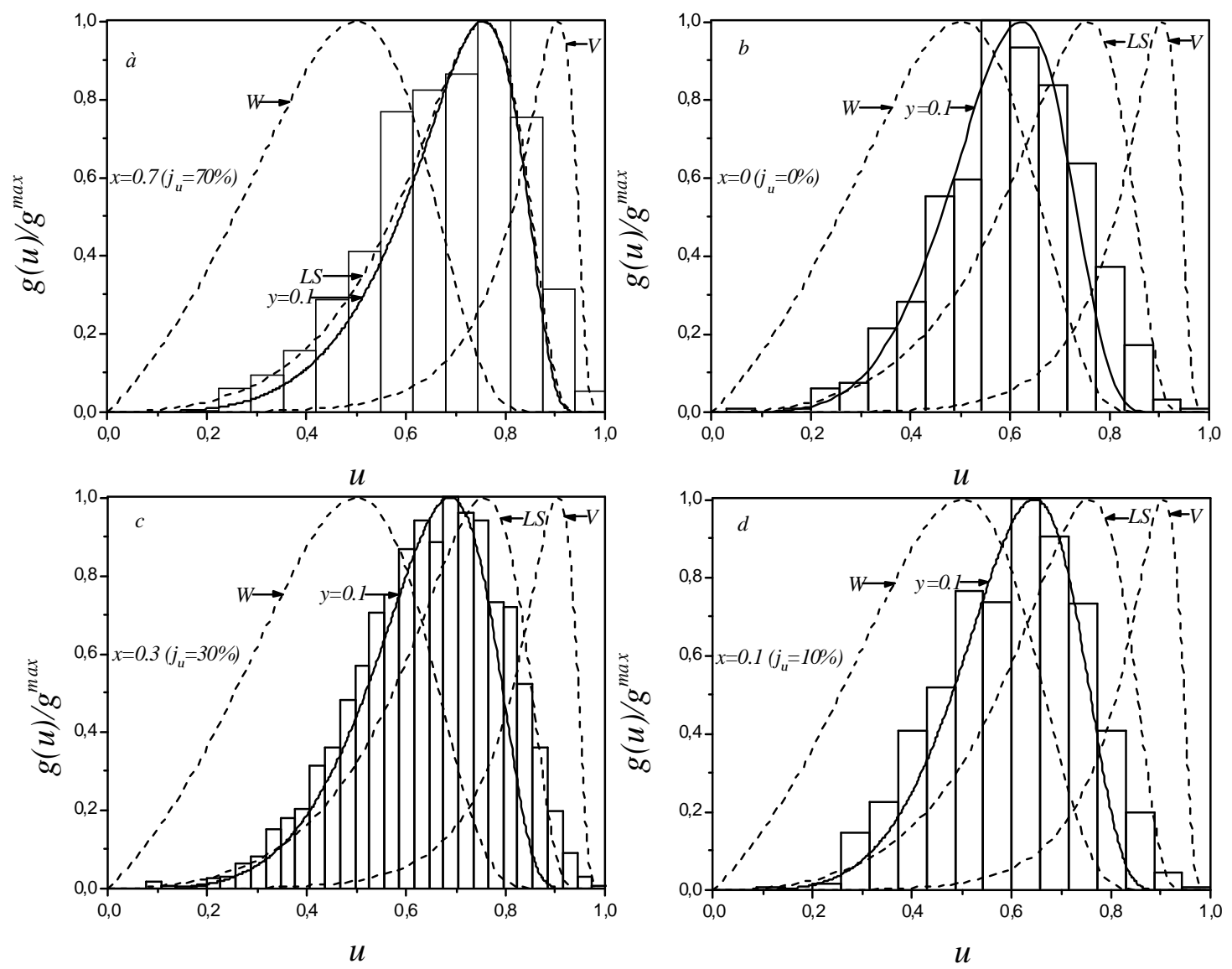

Fig. 7. A comparison of the theoretical curve $\left(73^{*}\right)$ with the size distribution of the $\mathrm{Al}_{3} \mathrm{Li} \mathrm{NP}\left(\delta^{\prime}\right.$-phase) in the $\mathrm{Al}-\mathrm{Li}$ alloys with different content of $\mathrm{Li}$ after thermal treatment at $225^{\circ} \mathrm{C}$ during: a) $-36(2.1$ atom \% $\mathrm{Li})$; b $)-$ $96 ; \mathrm{c})-240 ; \mathrm{d})-36(2.45$ atom $\% \mathrm{Li})$ hours [47].

For instance, a line for $y=0.4$ (Fig. $5 a$ ) corresponds to the following contributions into the total flux $j: j_{v}-$ $30 \% ; j_{d}-40 \% ; j_{i}-30 \%$. Thus, the theoretical curves in Fig. $5 a$ correspond to the particle size distributions involving all three fluxes $j_{v}, j_{d}$ and $j_{i}$. Same curves after normalization by their maximums are given in Fig. $5 b$.

Finally, the whole series of the theoretical curves calculated according to the distribution $g(u)=Q g^{\prime}(u)$ for all possible values of $x$ and $y$ is shown in Appendix 2. A comparison between experimental histograms and the theoretical curves corresponding to different values of $x$ and $y$ is given in Fig. 6. Both experimental and theoretical results are normalized by their respective maximums along both axes. The histograms in Fig. 6 represent the $\mathrm{Ni}_{3} \mathrm{Al}$ particle size distribution for the alloy $\mathrm{CuNi}_{15} \mathrm{Al}_{5}$ after processing at $450{ }^{\circ} \mathrm{C}$ during $\left.\left.\left.a\right)-24 ; b\right)-96 ; c\right)-380$ hours [46]. It can be noted that the particles size has decreased from 10 to $30 \mathrm{~nm}$ during this thermal treatment. The dotted lines represent various size distributions (W, LS and V) while the solid one shows the theoretical distribution corresponding to the values of $x$ and $y$ indicated in the figure.

As seen from Fig. 6, none of the W, LS or V distributions is in agreement with the experimental histograms. The closest agreement can be found for the theoretical distribution proposed in this paper $\left(73^{*}\right)$. In this case, the growth of $\mathrm{Ni}_{3} \mathrm{Al} \mathrm{NP}$ will be controlled by the Wagner's mechanism based on the rate of the interphase atoms transfer.

In case of the histograms related to the $\mathrm{Al}-\mathrm{Li}$ systems, the proposed theoretical distribution is in a satisfactory agreement with the experimental data (see Fig. $7 a, b, c)$. The theoretical curve (solid line) is compared with the experimental size distributions obtained for the $\mathrm{Al}_{3} \mathrm{Li} \mathrm{NP}$ ( $\delta^{\prime}$-phase of the Al-Li alloys containing 2.1 atom $\%$ of $\mathrm{Li})$. An aging of the alloys took place at $225{ }^{\circ} \mathrm{C}$ during $\left.\left.a\right)-36(\langle d\rangle \sim 41 \mathrm{~nm}) ; b\right)-96$ $(\langle d\rangle \sim 60 \mathrm{~nm}) ; c)-240(\langle d\rangle \sim 83 \mathrm{~nm})$ hours [47]. It is interesting to note that the LS distribution shows the best agreement with the experiment for shortest treatment time $(36 \mathrm{~h}$ ) (Fig. 7 a). It means that initially, the process of CL growing is controlled mainly by the matrix or bulk diffusion. As treatment time is increasing, the Wagner's mechanism becomes more and more influential (Fig.7 $b$, $c)$. 
A histogram of $\delta^{\prime}$-phase for the Al-Li alloys with increased content of $\mathrm{Li}$ (up to 2.45 atom \%) is given in Fig. $7 d$. Thermal treatment of these alloys was performed at $225^{\circ} \mathrm{C}$ during 36 hours. According to [47], no significant change in the mean size of the $\delta^{\prime}$-phase particles (45 nm vs $41 \mathrm{~nm}$ ) was registered for increase in the $\mathrm{Li}$ atom $\%$ from 2.21 to 2.25 . However, the mechanism of the $\mathrm{Al}_{3} \mathrm{Li} \mathrm{NP}$ growth changes: the $\mathrm{LS}$ curve can be applied to the $7 a$ case but cannot - to the 7 $d$ case. The theoretical distribution $\left(73^{*}\right)$ with respective $x$ and $y$ values should be applied to the latter system.

Therefore, we can state that the theoretical size distribution proposed in this paper can be adequately applied to a wide variety of experimental histograms for the alloys $\mathrm{CuNi}_{15} \mathrm{Al}_{5}$ and $\mathrm{Al}-\mathrm{Li}$ (more examples cannot be discussed here due to the article size limitations). It means that the mechanism describing growth of $\mathrm{CL}$ involving all three fluxes $j_{v}, j_{d}$ and $j_{i}$, can in fact be applied to real systems while the calculated size distribution $\left(73^{*}\right)$ should be used for comparison with some experimental histograms in order to determine possible mechanisms of the nanoparticles growth process.

\section{Conclusions}

As seen from some features of OR of the nanodispersed phases occurring in the metal alloys, an amount of the growth mechanisms and their nature provide a significant influence on the ripening kinetics. It has been found that if two mechanisms of growth controlled by the coefficients $D_{v}$ and $D_{d}$ corresponding to the diffusion fluxes $j_{v}, j_{d}$ are involved, the NP size distribution function depends on the adjustment coefficient $x$ used to fit theoretical distributions to each given set of experimental data.

When three growth mechanisms are involved (the two above mechanisms and the interphase kinetic flux $j_{i}$ ), the analysis becomes much more complicated. In this case, the size distribution functions falls into dependence on two parameters $x$ and $y$. On one hand, such comparison between experiment and theoretical calculations becomes more difficult, on the other - a theoretical curve corresponding to the experimental histograms can be found with more accuracy. As seen from the comparison between the experimental and theoretical size distributions, the NP growth mechanisms analyzed in this paper seem quite feasible during the process of Ostwald ripening.

Vengrenovich R.D. - PhD (Physical and Mathematical Science), Professor of the Department of Professional and Technological Education and General Physics;

Ivanskii B.V. - PhD (Physical and Mathematical Science), Teaching Assistant;

Stasyk M.O. - PhD (Physical and Mathematical Science), Associate Professor of the Department of Professional and Technological Education and General Physics;

Yarema S.V. - PhD (Candidate of Physical and Mathematical Science), Associate Professor of the Department of Professional and Technological Education and General Physics;

Moskalyuk A.V. - PhD (Physical and Mathematical Science), Associate Professor;

Kryvetskyi V.I. - PhD (Physical and Mathematical Science), Junior Research Fellow of the Department of Correlation Optics;

Fesiv I. V. - PhD (Physical and Mathematical Science), Associate Professor of the Department of Professional and Technological Education and General Physics.

[1] U. Hartmann, A Charm of Nanotechnology (BINOM, Laboratory of Knowledge, Moscow, 2008).

[2] W. Ostwald, Zs. Phys. Chem. 34, 495 (1900).

[3] I.M. Lifschitz, V. V. Slezov, J. Exper. \& Theor. Phys. 35, 479 (1958).

[4] I.M. Lifshits, V.V. Slesov, J. Phys. \& Chem. Solids 19 (1/2), 35 (1961).

[5] C. Wagner,Zeitschrift für elektrochemie 65 (7), 581 (1961).

[6] V.V. Slezov, Solid State Physics 9, 1187 (1967).

[7] H.O.K. Kirchner, Metall. Trans. 2, 2861 (1971) (doi.org/10.1007/BF02813264).

[8] B.K.Chakraverty, J. Phys. Chem. Solids 28, 2401 (1967) (doi.org/10.1016/0022-3697(67)90026-1).

[9] R.D. Vengrenovich, Ukr. J. Phys. 22, 219 (1977).

[10] H. Kreye, Zs. Metallkunde 61 (2), 108 (1970).

[11] A.J. Ardell, Acta Metall. 20, 602 (1972) (doi.org/10.1016/0001-6160(72)90015-6).

[12] R.D. Vengrenovich, Phys. Metal. \& Metal, Studies. 39 (2),436 (1975).

[13] R.D. Vengrenovich, Yu. V. Gudyma, S. V. Yarema, Phys. Metal. \& Metal, Studies. 91, 16 (2001).

[14] R.D.Vengrenovich, Yu.V.Gudyma, S.V. Yarema, Scripta Materialia 46, 363 (2002) (doi.org/10.1016/S13596462(01)01252-0).

[15] A.V. Koropov, Sci. Bull. of Sumy Univ. Series: Physics, Mathematics, mechanics 6, 01025 (2014).

[16] A.V. Koropov, Sci. Bull. of Sumy Univ. Series: Physics, Mathematics, mechanics 93, 49 (2006).

[17] A.V. Koropov, Solid State Phys. 50, 2093 (2008).

[18] A.V. Koropov, J. Nano- \& Electronic. Phys. 2, 31 (2010).

[19] A.V. Koropov. J. Exper. \& Theor. Phys. 81, 83 (2011).

[20] A. Markworth, Metall. Trans 4, 2651 (1973) (DOI: 10.1007/BF02644271).

[21] P.N. Ostapchuk, V.V. Slezov, V.V. Sagalovich, Physics of Radiation Damages and Radiation Material Studies. 28, 27 (1983). 
R.D. Vengrenovich, B.V. Ivanskii, M.O. Stasyk, S.V. Yarema, A.V. Moskaliuk, I.I. Panko, V.I. Kryvetskyi, I.V. Fesiv

[22] A.V. Koropov, V.V. Slezov, V.V. Sagalovich, Surface. Physics, Chemistry \& Mechanics 2, 63 (1982).

[23] A.M. Gusak, G.V. Lutsenko, Physics of Metals and Newest Technologies 25, 381 (2003).

[24] M.O. Pasichnyi, A.M. Gusak. Physics of Metals and Newest Technologies. 27, 1001 (2005).

[25] R.D. Vengrenovich, B.V. Ivanskii, A.V. Moskalyuk, J. Exper. \& Theor. Phys. 131, 1040 (2007).

[26] R.D.Vengrenovich, B.V. Ivanskii, A.V. Moskalyuk, [end etc.], Mass Transfer - Advanced Aspects, edited by Hironory Nakajama (In Tech - Open Access Publisher,Croatia, 2011).

[27] R.D. Vengrenovich, B.V.Ivanskii, I.I.Panko, M.O.Stasyk, J. Phys. Chem. C. 117, 13681 (2013) (doi.org/10.1021/jp402729h).

[28] R.D. Vengrenovich, B.V. Ivanskii, A.V. Moskalyuk, Ukr. J. Phys. 11, 1102 (2008).

[29] R.D. Vengrenovich, Acta Metall. 20, 1079 (1982) (DOI: 10.1016 / 0001-6160 (82) 90004-9).

[30] B.V. Ivanskii, A.V. Moskalyuk, S.V. Yarema, I.I. Panko, M.O. Stasyk, ISRN Nanomaterials 2013, 8 (2013).

[31] R.D.Vengrenovich,Yu.V. Gudymaand, S.V. Yarema, Scripta Materialia 46, 363 (2002) (doi.org/10.1155/2013/651576).

[32] T.Philippe, P.W. Voorhees, Acta Materialia 61, 4237 (2013) (doi.org/10.1016/ j.actamat.2013.03.049).

[33] H.Y. Jian, K.R. Elder, G. Hong, G. Martin, Phys. Rev. B. 47, 14110 (1993) (doi.org/10.1103/PhysRevB.47.14110).

[34] S.A.Kukushkin, D.A. Grigoriev, J. Phys. \& Chem. Solids 61, 1337 (2000) (DOI: 10.1016 / S0022-3697 (99) 00422-9).

[35] I.L.Maksimov, P.Y. Gubanov, Philosophical Magazine Letters 88, 115 (2008) (doi.org/10.1080/09500830701528727).

[36] A.V. Koropov, J. Nano- Electron. Phys 4, 03013 (2012).

[37] S. Sapra, D.D. Sarma, Phys. Rev. B. 69, 125304 (2004) (doi.org/10.1103/PhysRevB.69.125304).

[38] R. Viswanatha, H. Amenitsch, D.D. Sarma, J. Am. Chem. Soc. 129, 4470 (2007) (doi.org/10.1021/ja068161b).

[39] R. Viswanatha, P.K. Santra, C. Dasgupta, D.D. Sarma, Phys. Rev. Lett. 98, 255501 (2007) (doi.org/10.1103/PhysRevLett.98.255501).

[40] A.K. Simonyan, J. Contemp. Phys. 48, 220 (2013) (DOI: 10.3103 / S106833721305006X).

[41] R.D.Vengrenovich, B.V. Ivanskii, I.I. Panko, Yu.M. Kushnir, V.I.Kryvetskyi, J. Contemp. Phys. 49, 158 (2014) (DOI: 10.3103/S1068337214040045).

[42] S. Gwo, Ch.P. Chou, Ch.L. Wu etc. Phys. Rev. Lett. 90, 185506 (2003) (DOI:10.1103 / PhysRevLett.90.185506).

[43] R.D. Vengrenovich, B.V. Ivanskii, A.V. Moskalyuk, Opto-electronics review 18, 168 (2010) (DOI: 10.2478/s11772-010-0001-3).

[44] R.D. Vengrenovich, B.V. Ivanskii, S.V. Yarema, I.I. Panko, M.O. Stasyk, A.V. Moskalyuk, Applied Optics 53, B87 (2014) (doi.org/10.1364/AO.53.000B87).

[45] G.M. Novotny, A.J. Ardell, Material Science and Engineering A. 318, 144 (2001).

[46] J.P.Stobrawa, Z.M. Rdzawski, Journal of Achievements in Materials and Manufacturing Engineering 15, 21 (2006).

[47] B.A. Pletcher, K.G. Wang, M.E. Glicksman, Acta Materialia 60, 5803 (2012) (DOI: 10.1016/j.actamat.2012.07.021). 


\section{Р.Д. Венгренович, Б.В. Іванський, М.О. Стасик, С.В. Ярема, А.В. Москалюк,} B.I. Кривецький, I.B. Фесів

\section{Оствальдівське дозрівання нанодисперсних фаз в металевих сплавах (огляд)}

Чернівецький наџіональний університет ім. Ю. Федьковича, 58012, Чернівці, Украӥна, е-таіl: оffice@ chnи.еdи.иа

В огляді проведено аналіз кінетики оствальдівського дозрівання нанодисперсних фаз в металевих сплавах, за умови, що ріст (розчинення) наночастинок зміцнюючої фази контролюється одночасно матричною дифузією, дифузією вздовж дислокаційних трубок і швидкістю переходу атомів через міжфазну границю розділу (вагнерівський механізм росту). Встановлено, що загальною закономірністю різних механізмів росту (розчинення) наночастинок в процесі дозрівання $\epsilon$ ïх не поодинока дія, а одночасна. Кількість задіяних механізмів росту (один, два, три) залежить від багатьох факторів, зокрема: хімічного складу нанодисперсної фази, умов експлуатації (зміни механічних навантажень, температурних режимів, зовнішнього середовища), технологічних умов синтезу тощо. Показано, що коли ріст (розчинення) наночастинок в процесі оствальдівського дозрівання контролюється одночасно коефіцієнтом матричної дифузії $D_{v}$ і коефіцієнтом дифузії вздовж дислокацій $D_{d}$, то відповідна функція розподілу частинок за розмірами залежить від одного параметру $x$, який змінюється в межах $0 \leq x \leq 1$, де $x$ - визначає співвідношення між дифузійним $j_{v}$ і дислокаційним $j_{d}$ потоками. У випадку, коли одночасно діють три механізми росту (розчинення), загальний потік $j$, який відповідає масообміну між частинками і матрицею, складається із трьох частин: $j=j+j_{d}+j_{i}$, де кінетична складова $j_{i}$ визначається кінетичним коефіцієнтом $\beta$. Тоді відповідна функція розподілу наночастинок за розмірами залежить від двох параметрів $x$ і $y$, які визначають співвідношення між дифузійним $\left(j^{\prime}=j_{v}+j_{d}\right)$ i кінетичним $j_{i}$ потоками $(0 \leq x, y \leq 1)$. Можливість реалізації на практиці пропонованих механізмів росту наночастинок в процесі оствальдівського дозрівання може бути підтверджена або спростована шляхом порівняння експериментальних і теоретичних даних. Приведені в огляді результати співставлень експериментальних гістограм 3 теоретично розрахованими кривими вказують на реалістичність пропонованих механізмів укрупнення наночастинок дисперсних фаз в процесі дозрівання.

Ключові слова: наночастинка, оствальдівське дозрівання, теорія Ліфшица-СльозоваВагнера, нанокристал, кластер, функція розподілу за розмірами. 
R.D. Vengrenovich, B.V. Ivanskii, M.O. Stasyk, S.V. Yarema, A.V. Moskaliuk, I.I. Panko, V.I. Kryvetskyi, I.V. Fesiv

Appendix 1

Let us decompose the third order polynomial in the denominator of (75) by $u$

$$
u^{3}+u^{2}\left(4 y x-y+x+3 y^{2}+x^{2}\right)+u\left(3 y^{2}+y x\right)+y(3 y+x+1)=(u+b)\left(u^{2}+c u+d\right),
$$

where the root of cubic equation (A1) calculated by Cardano formulas:

$$
\begin{gathered}
b=\frac{\mu}{3}-w-v, \\
\mu=3 y^{2}+x^{2}+4 y x-y-x, w=\sqrt{-\frac{q}{2}+\sqrt{z}}, v=\sqrt{-\frac{q}{2}-\sqrt{z}}, q=\frac{2 \mu^{3}}{27}-\frac{\mu s}{3}+t, s=3 y^{2}+y x, t=3 y^{2}+y x+y, \\
z=\left(\frac{p}{3}\right)^{3}+\left(\frac{q}{2}\right)^{3}, p=\frac{3 s-\mu^{2}}{3} \text { and coefficients } \\
c=\frac{2}{3} \mu+w+v, \quad d=\left(\frac{w+v}{2}\right)^{2}+\left(\frac{w+v}{3}\right) \mu+\left(\frac{\mu}{3}\right)^{2}+\frac{3}{4}(w-v)^{2} .
\end{gathered}
$$

After decomposition to the simple terms, the equation (75) can be rewritten as

$$
\frac{d g^{\prime}(u)}{g^{\prime}(u)}=\frac{\sigma}{u}+\frac{\alpha}{1-u}+\frac{\omega}{(1-u)^{2}}+\frac{\beta}{u+b}+\frac{\gamma u+\varepsilon}{u^{2}+c u+d} .
$$

Then the coefficients $\sigma, \alpha, \omega, \beta, \gamma, \varepsilon$ should be defined before integration of (A4). Let us reduce all terms in the right part of (A4) to a common denominator and then equate all coefficients at the terms with corresponding orders of $u$ in the numerators of (75) and (A4). As a result, a system of equations will be obtained for determination of the coefficients values:

$$
\left\{\begin{array}{l}
\gamma+\beta+\sigma-\alpha=-4 \\
\sigma(c+b-2)+\alpha(1-b-c)+\omega+\beta(c-2)+\gamma(b-2)+\varepsilon=0 \\
\sigma(b c-2 c+d-2 b+1)+\gamma(c+b-b c-d)+\omega(c+b)+\beta(d-2 c+1)+\gamma(1-2 b)+ \\
+\varepsilon(1-2 b)=k_{1} \\
\sigma(b-2 d+c-2 b c+b d)+\alpha(b c-b d+d)+\omega(b c+d)+\beta(c-2 d)+\gamma b+\varepsilon(1-2 b)=k_{2} \\
\sigma(b c-2 b d)+\alpha b d+\omega b d+\beta d+\varepsilon b=-k_{3} ; \\
\sigma b d=k_{4}
\end{array}\right.
$$

where $k_{1}=2 y-7 y x-2 x^{2}-3 y^{2}+1-2 x, k_{2}=6 y x+2 x^{2}+2 x, k_{3}=9 y^{2}+6 y+3 y x, k_{4}=4 y+4 y x+12 y^{2}$.

Having resolved (A5), the following expressions can be obtained:

$$
\begin{gathered}
\sigma=\frac{k_{4}}{b d}, \\
\alpha=-\frac{k_{1}(d+2 b d-1+b c)+k_{2}(b d-c-b-2)+k_{3}(d+2 b+2 c+3+b c)}{\left(2 b+1+b^{2}\right)(1+d+c)^{2}}+ \\
+\frac{k_{4}(-2 d-3 c-3 b-4-b d-2 b c)-4(3 b c+4 b d+3 d+2 c+2 b+1)}{\left(2 b+1+b^{2}\right)(1+d+c)^{2}} \\
\beta=-\frac{b k_{3}+k_{4}+4 b^{5}+b^{2} k_{2}-b^{3} k_{1}}{b\left(-2 b^{2} c+2 b d+d+b^{2} d+b^{4}-b c+b^{2}+2 b^{3}-b^{3} c\right)}, \\
\omega=-\frac{3}{(b+1)(1+d+c)}, \\
+\frac{k_{4}\left(c^{3}-2 d+c-b+b d-2 b c+2 c^{2}-2 d c-b c^{2}\right)+4 d\left(2 b d c^{2}-d c^{2}-2 d^{2} c-2 b d c+b c^{3}+b d^{2} c+d^{2}-d^{3}-2 b d^{2}\right)}{2 d\left(2 d c+c^{2}+2 c+2 d+1+d^{2}\right)\left(b^{2}-b c+d\right)}, \\
\varepsilon=-\frac{d^{2} k_{1}(d c-b d+2 d+b)+d^{2} k_{2}\left(d+b c-2 c-c^{2}+2 b-1\right)+d k_{3}\left(2 d-c^{3}-b d+2 d c-2 c^{2}+b c^{2}+b-c+2 b c\right)+}{\left(2 d c+c^{2}+2 c+2 d+1+d^{2}\right) d\left(b^{2}-b c+d\right)} \\
\frac{k_{4}\left(c\left(3 d c-c-c^{3}+b+b c^{2}+2 b c+4 d-2 c^{2}-2 b d\right)+d(-2 b-d+1)\right)+4 d^{2}\left(b d-2 b d c+d c-b d^{2}-b c^{2}+2 d^{2}\right)}{\left(2 d c+c^{2}+2 c+2 d+1+d^{2}\right) d\left(b^{2}-b c+d\right)}
\end{gathered},
$$


Appendix 2
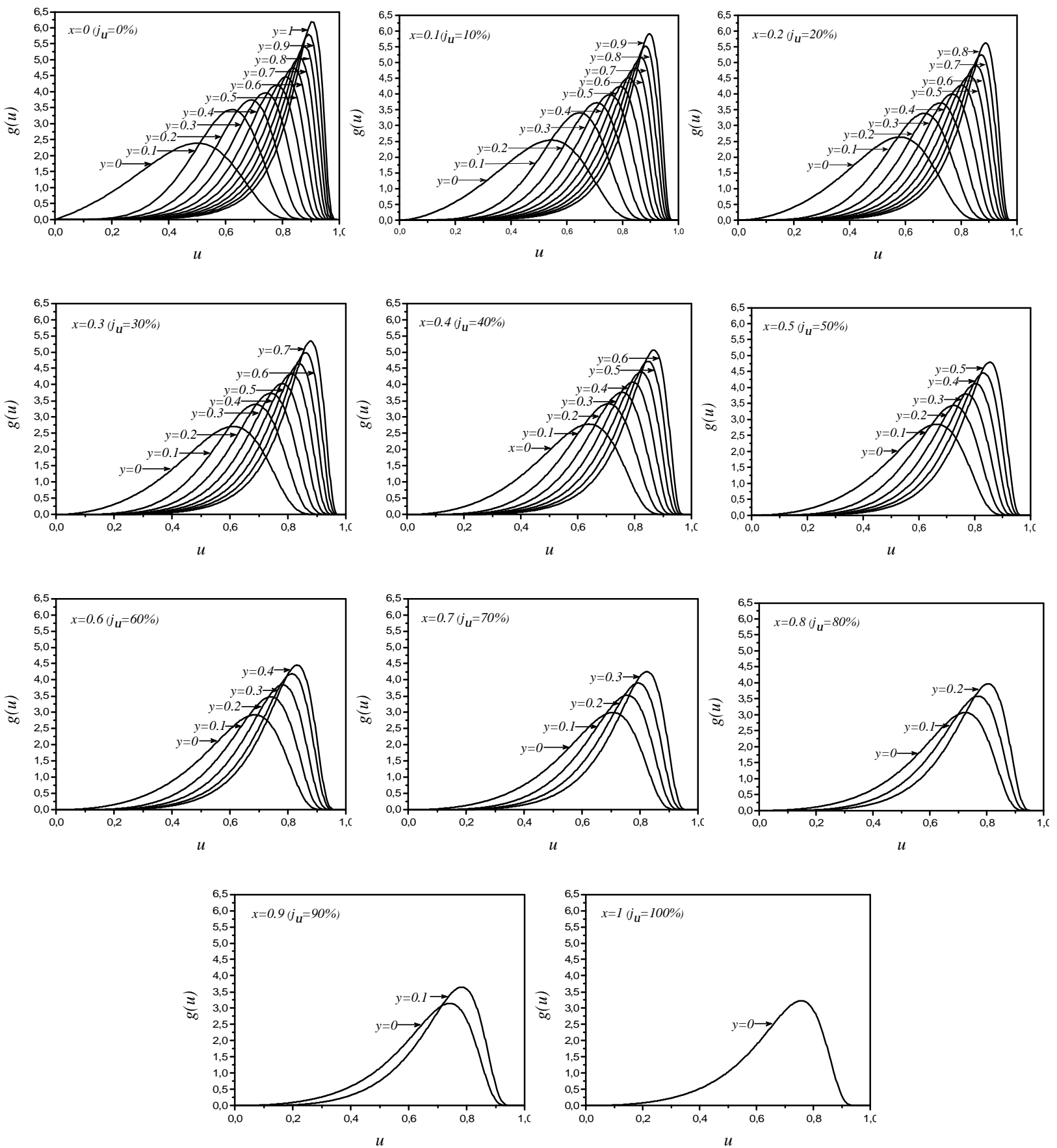

Fig. 1. A2. The whole series of the theoretical curves calculated according to the distribution $\left(73^{*}\right)$ for all possible values of $x$ and $y$ 